\title{
Investigation On The Influence of A Novel Redirector With By-Pass Damping On The Performance of Load Sensing Steering System
}

\section{Yu-Qi Wang}

Jilin University https://orcid.org/0000-0001-6670-4295

Xin-Hui Liu

Jinlin University

Jin-Shi Chen ( $\square$ spreading@jlu.edu.cn )

Dong-Yang Huo

Jilin University

Original Article

Keywords: Articulated vehicle, Redirector, Load sensing steering system, Pressure oscillation

Posted Date: June 15th, 2020

DOI: https://doi.org/10.21203/rs.3.rs-34952/v1

License: (c) (i) This work is licensed under a Creative Commons Attribution 4.0 International License.

Read Full License 


\section{Title page}

\section{Investigation on the Influence of a Novel Redirector with By-pass Damping on the Performance of Load Sensing Steering System}

Yu-Qi Wang, born in 1993, is currently a PhD candidate at School of Mechanical and Aerospace Engineering, Jilin University, China She received bachelor's degree from Jilin University, China, in 2016. Her research interests include fluid power transmission and control.

Tel: +86-188-44197058; E-mail: yuqiw18@mails.jlu.edu.cn

Xin-Hui Liu, born in 1962, is currently a professor at School of Mechanical and Aerospace Engineering, Jilin University, China.

Jin-Shi Chen, born in 1983, is currently an associate professor at School of Mechanical and Aerospace Engineering, Jilin University, China.

E-mail: spreading@jlu.edu.cn

Dong-Yang Huo, born in 1996, is currently a master candidate at School of Mechanical and Aerospace Engineering, Jilin University, China.

Corresponding author: Jin-Shi Chen E-mail: spreading@jlu.edu.cn 


\title{
Investigation on the Influence of a Novel Redirector with By-pass Damping on the Performance of Load Sensing Steering System
}

\author{
Yu-Qi Wang ${ }^{1}$ Xin-Hui Liu' ${ }^{1}$ Jin-Shi Chen ${ }^{1}$ • Dong-Yang Huo
}

Received June xx, 201x; revised February xx, 201x; accepted March xx, 201x

(C) Chinese Mechanical Engineering Society and Springer-Verlag Berlin Heidelberg 2020

\begin{abstract}
The load sensing steering system of articulated loaders is prone to large pressure shock and oscillation during steering operations, affecting the stability of the steering system. To improve this phenomenon, an optimized structure of the redirector with by-pass damping is proposed, which adding orifices and throttle grooves to the original redirector. In the study, to control the steering load and working conditions, the steering load of the loader is replaced by using a pressure regulating valve. The simulation and experimental results shows that, compared with the traditional redirector, using the novel structure redirector with by-pass damping ensures good load sensing characteristics, the peak output pressure shock caused by the load unit step signal decreases from 65.04 bar to 56.35 bar, with a decrease rate of $13.4 \%$, reducing the pressure oscillation of the hydraulic system. The pressure fluctuation time can be reduced from $2.09 \mathrm{~s}$ to $1.6 \mathrm{~s}$, with a decrease rate of $23.4 \%$, the output pressure oscillation decays faster, the smoothness of the steering operation is significantly improved.
\end{abstract}

Keywords: Articulated vehicle - Redirector - Load sensing steering system $\bullet$ Pressure oscillation

\section{Introduction}

The loader is mainly used for loading and unloading materials and shoveling work within a certain range [1-2]. During the operation, frequent steering operations are required. The articulated loader is widely used due to its compact structure and easy operation. Scholars have conducted a comprehensive study on the steering system of

Jin-Shi Chen

spreading@jlu.edu.cn

1 School of Mechanical and Aerospace Engineering, Jilin University, 130022, Jilin, China articulated vehicles using numerical analysis and simulation methods [3-5]. More accurate steering performance and the main parameters affecting the performance were obtained. During steering operation of the existing articulated loader, when the driver turns the steering wheel, there are some unstable situations such as shocks and oscillations in the hydraulic system, resulting in poor stability of the machine when starting and stopping the steering. The higher the steering wheel speed, the more obvious the shaking or shimmy of the fuselage [6-7].

The optimization of steering system performance has also become a focus of scholars' research. Reference [8] introduced the steering method into the study of the steering system, combined the dynamic model with the physical model, and used the NSGA-II algorithm to optimize the steering system for further improve the performance of the system. A novel steering system has been developed to improve the driving performance during steering [9]. References [10-11] optimized the articulated frame to obtain a more compact articulated frame steering system, improving steering flexibility.

For the unstable situation of the hydraulic system, the introduction of a steering system with independent control of the inlet and outlet ports has improved the steering stability and steering sensitivity under high torque [12]. The load sensing pump [13], the proportional variable pump [14]-[17] and other variable displacement pump were used to replace the fixed displacement hydraulic pump for the single-rod hydraulic cylinder steering system [18] -[21] and the double-rod hydraulic cylinder steering system [22] to build a closed-loop steering system. The displacement of the pump was controlled by the rotation speed of the steering wheel, which can supply oil on demand, reduce the loss of the steering system and 
improve the stability of the steering system. Caterpillar studied working and steering flow sharing hydraulic systems with the flow sharing valve [23]. The steering scheme of installing a by-pass proportional throttle valve at the outlet of a fixed displacement hydraulic pump was proposed in reference [24]. By-pass throttling reduces the outlet pressure of the hydraulic pump and the pressure shock of steering operating. Sany, Liugong and other companies mainly studied the improvement of the full-hydraulic steering system and load sensing hydraulic steering system with flow amplification valve [25-27]. EATON has done a lot of research on the structure optimization of the full hydraulic redirector, developed a full hydraulic redirector that can eliminate oil trapping [28]. Lanzhou University of Technology has done a lot of work on the development of the steering priority flow amplification valve and the structure optimization of the load sensing priority valve [29].

Based on the above research, scholars have researched and optimized hydraulic systems and components. Appropriately adjusted the oil supply pressure of the system, eliminated the oil trapped, which to some extent alleviated the pressure shock, oscillation and other instability of articulated vehicles during steering. However, under high speed condition, it is still difficult to control the pressure shock caused by the sudden flow changes, and the steering system will still have a large oscillation. For this reason, a redirector structure with by-pass damping is proposed.

The structure of this paper is as follows: Section 2 introduces the working principle of the redirector with by-pass damping. Section 3 deduces the relationship between the valve port area of the redirector and establishes a mathematical model. To research the relationship between the flow rate, the pressure and rotation speed of the redirector. In Section 4, the simulation model of the redirector with by-pass damping is established and verified the performance, the simulation results are obtained. Section 5 builds a simulation experimental platform and obtains experimental results of the by-pass damping redirector. Section 6 analyzes the dynamic characteristics and oscillation analysis of the novel redirector and the original redirector. Section 7 is the conclusion.

\section{Working Principle}

The research object of this paper is the coaxial flow rate amplification redirector, whose structure is shown in Figure 1 (a). It is mainly composed of three parts: housing, metering motor and rotary valve (including control spool

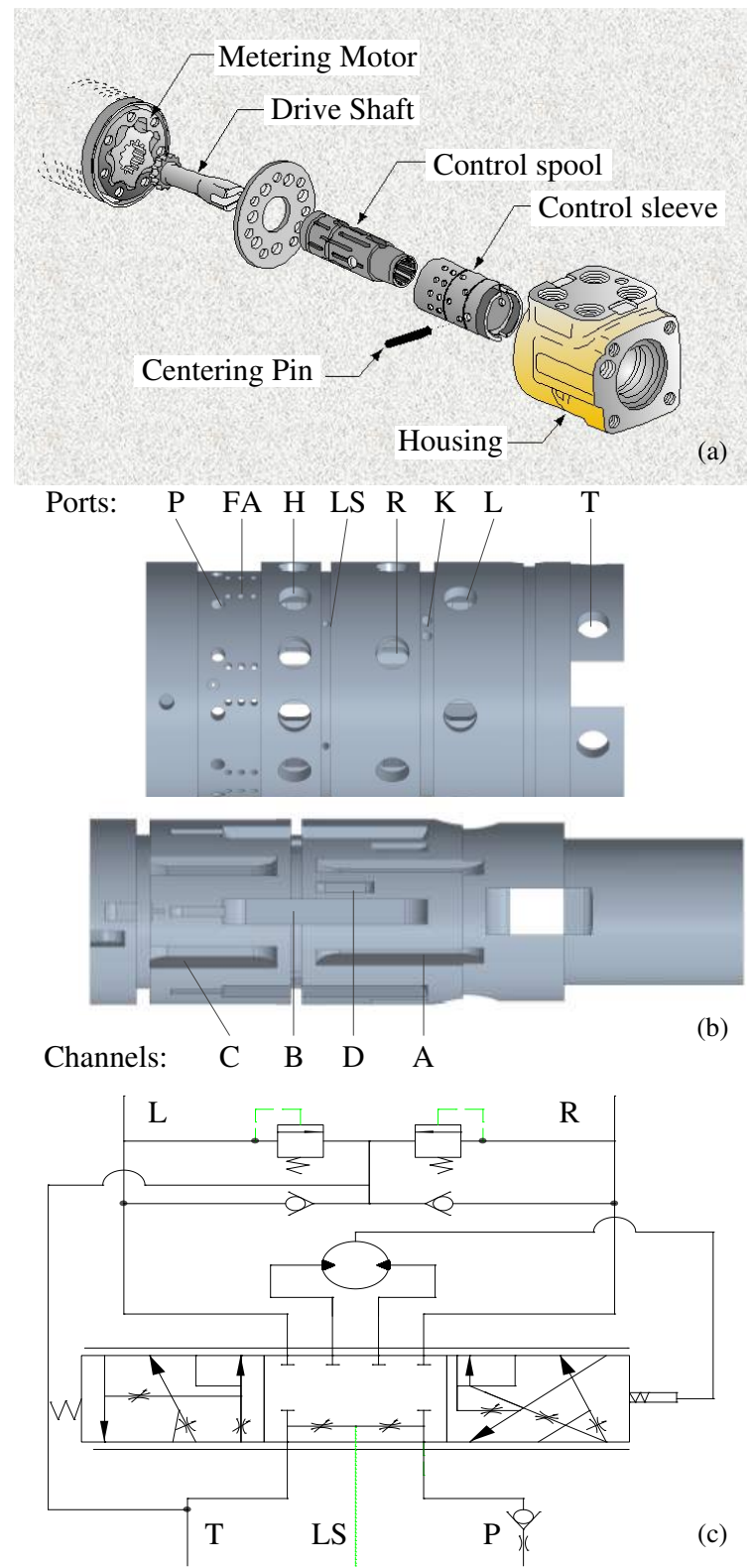

Figure 1 Schematic diagram of the redirector. (a) Structure of the redirector; (b) Structure of the rotary valve; (c) Principle diagram of the redirector.

and control sleeve). The control spool of the redirector is connected to the steering wheel, and the control spool rotates synchronously when the steering wheel is turned. There is a relative angular displacement between the control spool and the control sleeve. The input $\mathrm{P}$ opens after the control spool rotates a certain angle. The fluid enters through the input and pushes the metering motor to rotate. The metering motor is mainly used to ensure that the flow rate of oil delivered by the redirector is proportional to the steering wheel angle when the steering pump is working. If the steering pump is not working, the 
motor directly sucks oil from the oil tank and supplies it to the steering cylinder when rotating the steering wheel.

The metering motor is mainly used to ensure that the flow rate of oil delivered by the redirector is proportional to the steering wheel angle when the steering pump is working; when the steering pump is not working, manually turn the steering wheel, the motor directly sucks oil from the oil tank and supplies it to the steering cylinder. The faster the rotation speed of the steering wheel, the greater the relative angular displacement of the control spool and control sleeve, the flow rate is greater, and the steering speed is faster. The rotary valve is mainly composed of a control spool with four groups of grooves and a control sleeve with ten groups of through holes. When the control spool rotates, the direction and flow rate of the oil are changed by the on-off and opening area of different grooves and through holes, as shown in Figure 1 (b).

Figure 1 (c) is the principle diagram of the redirector. When the steering wheel is not rotated, the redirector is in the medium position, and the port $\mathrm{P}$ is disconnected to ports $\mathrm{R}$ and $\mathrm{L}$. The oil enters the channel $\mathrm{C}$ through ports $\mathrm{P}$ and LS and returns to the tank through the port T. The steering rod drives the control spool to rotate when the steering wheel rotates to the left. The oil enters the even-column $\mathrm{H}$ of the $\mathrm{C}$ channel through the $\mathrm{P}$ port and reaches the metering motor, then output from the odd-column $\mathrm{H}$ through the $\mathrm{B}$ channel and the $\mathrm{L}$ port to the steering cylinder. The port $\mathrm{T}$ is closed, the channel A connects the port LS, port R and the fuel tank, and the left steering is completed. When the steering wheel rotates at high speed, the steering rod drives the control spool to rotate a large angle, the oil enters the channel B through flow rate amplification holes and is directly output from parts $\mathrm{L}$ and $\mathrm{R}$ of the redirector to the steering cylinder to complete the steering. When the redirector is in the medium position, the by-pass damping hole is not connected to the port $\mathrm{R}$ or $\mathrm{L}$. When the steering wheel rotates, the port $\mathrm{R}$ or $\mathrm{L}$ is connected to the port $\mathrm{T}$ through the by-pass throttle hole K. At this time, the pressure shock and oscillation caused by the displacement of the cylinder can be reduced by by-pass damping to achieve smooth steering.

\section{Methodology and Model}

\subsection{Calculation of the Opening Area}

It is necessary to calculate the opening area of each port and channel when researching the performance of the redirector. For the convenience of calculation, the

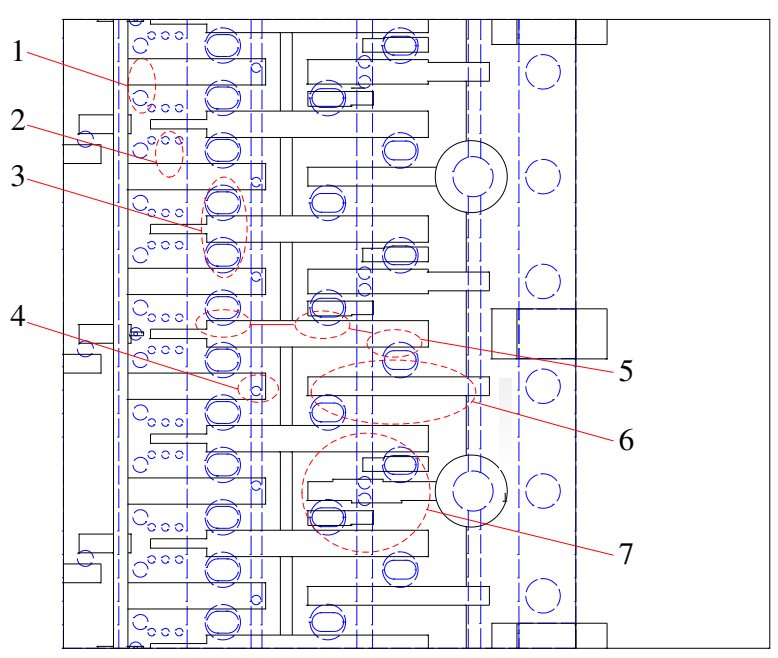

Figure 2 Expanded view of control spool and sleeve. 1. Inlet module; 2. Flow rate amplification module; 3. Metering motor module; 4. Load sensor module; 5. Working module; 6. Return module; 7. By-pass module.

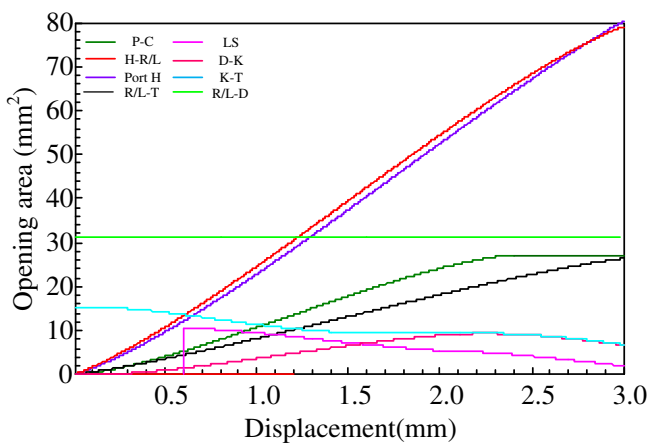

Figure 3 Relation between the opening area of each module and the control spool displacement

assembly of the control spool and control sleeve along the axis is expanded, as shown in Figure 2. The channel portion of the control sleeve is indicated by solid lines, and the control spool portion is indicated by dotted lines. The through hole on the control spool is evenly distributed along the circumference, and 12 holes in each of $\mathrm{P}$ and $\mathrm{H}$ are distributed along the same center line. Holes $\mathrm{H}$ are numbered from left to right, odd-columns are aligned with the center line of holes $\mathrm{L}$ and even-columns are aligned with the center line of holes $\mathrm{R}$. The position of by-pass damping holes $\mathrm{K}$, holes LS and flow rate amplification holes are shown in the figure and the other through holes are T. There are 6 channels in each of A、B、C and D on the control sleeve distributing along the circumference. Channel A controls the on-off of L-T or R-T. Channel C controls the on-off of P-T and feedback of LS. Channel B is evenly distributed between channels $\mathrm{A}$ and $\mathrm{C}$ to control 
the on-off of $\mathrm{R}-\mathrm{H}$ or $\mathrm{L}-\mathrm{H}$ and realize the performance of flow rate amplification. Channel $\mathrm{D}$ controls the on-off of L-K or R-K.

The oil flow path of the redirector is divided into 7 modules. The opening area of the inlet module P-C is

$$
A_{P}=\left\{\begin{array}{cc}
3 r^{2}(\theta-\sin \theta) & (0<x<2 r) \\
6 \pi r^{2} & (2 r<x)
\end{array}\right.
$$

where $\theta=2 \arccos \frac{r-x}{r}, r$ is diameter of the hole, $\theta$ is the angle corresponding to the opening area.

The opening area of the flow rate amplification module $\mathrm{A}-\mathrm{C}$ is

$$
A_{P A}=\left\{\begin{array}{cc}
9 r^{2}(\theta-\sin \theta) & \left(0<x<x_{1}\right) \\
6 r^{2}(\theta-\sin \theta)+\left(\frac{3}{2} \theta+1.02\right) r^{2} & \left(x_{1}<x<x_{2}\right) \\
-1.5 r^{2} \sin \theta-3(r-x) & \left(x_{2}<x\right) \\
18 \pi r^{2}\left(\frac{3}{2} \theta+1.02\right) r^{2}-6 r^{2}(\theta-\sin \theta) & \\
+18 \pi r^{2}-1.5 r^{2} \sin \theta-3(r-x) &
\end{array},\right.
$$

where $x_{1}, x_{2}$ are displacements of two limit positions.

The opening area of the metering motor module when the oil goes through the inlet and outlet $\mathrm{H}$ of the metering motor is

$$
A_{H}=\left\{\begin{array}{cc}
1.5 r^{2}(\theta-\sin \theta)+3 x l & (0<x<2 r) \\
3 r(l+\pi r) & (2 r<x)
\end{array}\right.
$$

where $l$ is the side length of motor hole.

The opening area of the working module H-R\L is

$$
A_{R \backslash L}=\left\{\begin{array}{cc}
3 r^{2}(\theta-\sin \theta)+6 x l & (0<x<5 r) \\
6 r(2 l+\pi r) & (5 r<x)
\end{array},\right.
$$

The opening area of the return module $\mathrm{R} \backslash \mathrm{L}-\mathrm{T}$ is

$$
A_{T}=\left\{\begin{array}{cc}
r^{2}(\theta-\sin \theta)+2 x l & (0<x<a) \\
r^{2}(\theta-\sin \theta)+6 x l+2 r^{2}\left(\theta_{1}-\sin \theta_{1}\right) & (a<x<2 r-a)
\end{array}\right.
$$

where $\theta_{1}=2 \arccos \frac{r-x+a}{r}$

The opening area of the load sensor module when oil through LS is

$$
A_{L S}=\left\{\begin{array}{cc}
6 \pi r^{2} & (x<a) \\
6 \pi r^{2}-\frac{3}{2} r^{2}(\theta-\sin \theta) & (a<x<a+l) \\
3 \pi r^{2}-\frac{3}{2} r^{2}(\theta-\sin \theta) & (a+l<x<a+l+2 r) \\
0 & (a+l+2 r<x)
\end{array}\right.
$$

where $a$ is the transverse distance of opening area.

The opening area of the by-pass module RlL-D is

$$
A_{D}=\left\{\begin{array}{cc}
3 l(a-x)+\frac{3}{2} r^{2}(\theta-\sin \theta) & (0<x<a) \\
0 & (a<x)
\end{array}\right.
$$

The opening area of the by-pass module $\mathrm{D}-\mathrm{K}$ is

$$
A_{D-K}=\left\{\begin{array}{cl}
\frac{1}{2} r^{2}(\theta-\sin \theta) & (0<x<a) \\
\frac{1}{2} r^{2}(\theta-\sin \theta)+r^{2}\left(\theta_{1}-\sin \theta_{1}\right) & (a<x<2 r) \\
\pi r^{2}+r^{2}\left(\theta_{1}-\sin \theta_{1}\right) & (2 r<x<l) \\
\frac{1}{2} r^{2}\left(\theta_{2}-\sin \theta_{2}\right)+r^{2}\left(\theta_{1}-\sin \theta_{1}\right) & (1<x<2 r+a) \\
\frac{1}{2} r^{2}\left(\theta_{2}-\sin \theta_{2}\right)+2 \pi r^{2} & (2 r+a<x<a+l) \\
\frac{1}{2} r^{2}\left(\theta_{2}-\sin \theta_{2}\right)+r^{2}\left(\theta_{3}-\sin \theta_{3}\right) & (a+l<x<l+2 r)
\end{array}\right.
$$

where $\theta_{2}=2 \arccos \frac{x-r-l}{r}, \theta_{3}=2 \arccos \frac{x-a-r-l}{r}$

The opening area of the by-pass module $\mathrm{K}-\mathrm{T}$ is

$$
A_{K}=\left\{\begin{array}{cc}
\frac{3}{2} r^{2}\left(\varphi_{1}-\sin \varphi_{1}\right)+\frac{3}{2} r^{2}\left(\varphi_{2}-\sin \varphi_{2}\right) & \left(0<x<2 r-l_{2}\right) \\
3 \pi r^{2}+\frac{3}{2} r^{2}\left(\varphi_{1}-\sin \varphi_{1}\right) & \left(2 r-l_{1}<x<l_{1}\right) \\
3 \pi r^{2} & \left(l_{1}<x<l_{3}\right) \\
\frac{3}{2} r^{2}\left(\varphi_{3}-\sin \varphi_{3}\right) & \left(l_{3}<x<2 r+l_{3}\right)
\end{array}\right.
$$




$$
\begin{aligned}
& \varphi_{1}=2 \arccos \frac{r+x-l_{1}}{r} \quad, \quad \varphi_{2}=2 \arccos \frac{r-x-l_{2}}{r}, \\
& \varphi_{3}=2 \arccos \frac{x-l_{3}-r}{r} .
\end{aligned}
$$

where $l_{1}, l_{2}$ are distances between two limit positions and two holes, $l_{3}$ is the distance between the two holes.

The relationship curve between the opening area of each module and the control spool displacement is shown in Figure 3.

\subsection{Mathematical Model of the Redirector}

For the purpose of further analyzing the dynamic characteristics of the redirector with by-pass damping structure, the mathematical model of the redirector is established. The following assumptions are accepted, ignore the pipeline loss, internal leakage, friction and hydraulic force of the redirector which have little effect on steering performance. According to the structure and working principle of the redirector, the schematic diagram of the equivalent damping is shown in Figure 4.

The combination of the metering motor seal oil cavity and the hole and channel structure of the rotary valve realizes the oil distribution relationship of the redirector. The flow rate continuity equation of the metering motor without considering leakage is

$$
q_{m}=D_{m} \dot{\theta}_{m}
$$

where $\dot{\theta}_{m}$ is the angular velocity of motor, $D_{m}$ is the displacement of motor.

During the working process of the redirector, it is mainly subjected to pressure uniformly distributed in the radial direction [30]. Since the control sleeve of the redirector is rigidly connected to the rotor of the motor, the force condition of the redirector is the same as that of the metering motor. According to the working principle of the redirector, the viscous friction and drag torque between the control sleeve and control spool of the rotary valve are main loads of the motor. The viscous friction can be ignored because it is much smaller than the drag torque. The force balance equation of the motor is

$$
T_{l}=D_{m}\left(P_{H 1}-P_{H 2}\right)
$$

where $P_{i}$ is the pressure between each orifice in rotary valve.

The control spool and control sleeve of the redirector are expanded into a planar structure according to their axial direction. The displacement of the control spool is

$$
x_{z}=\frac{d}{2}\left(\int_{0}^{t} \omega_{f} d t-2 \pi \int_{0}^{t} \frac{q_{m}}{D_{m}} d t\right)=x_{z}\left(\omega_{f}\right)
$$

where $\omega_{f}$ is the angular velocity of the rotary valve.

The differential pressure and flow rate of the redirector inlet are

$$
\begin{gathered}
\Delta P=P-P_{L S}, \\
q_{1}=C_{d} A_{1}\left(x_{z}\right) \sqrt{\frac{2 \Delta P}{\rho}},
\end{gathered}
$$

where $C_{d}$ is the flow coefficient, $\rho$ is density of oil.

According to the previous research and analysis of priority valves and redirectors [31-32], the differential pressure of the redirector orifice is basically a constant value. The flow rate through the inlet is only related to the opening area of the rotary valve, that is, it is related to the rotation speed of the control spool of the steering gear, and has nothing to do with the electromotor speed and steering load.

The flow rate of the redirector through each damping hole can be expressed

$$
q_{i}=C_{d} A_{i}\left(x_{z}\right) \sqrt{\frac{2 \Delta P_{i}}{\rho}}
$$

where $A_{i}$ is the area of orifice, $\Delta P_{i}$ is the pressure drop through each orifice.

When the redirector is in the medium position, medium damping holes $R_{2}, R_{3}$ are working, other damping holes are in a negative opening state, and $P_{L S}$ is low pressure.

$$
q_{z}=q_{2}=q_{3},
$$

When the redirector rotates, $R_{2}, R_{3}$ are closed. The flow rate of each damping hole is

$$
\begin{gathered}
q_{z}=q_{7}=q_{1}+q_{6}=q_{9}=q_{L-R}+q_{8}, \\
q_{m}=q_{1}=q_{4}=q_{5},
\end{gathered}
$$

As can be seen from Figure 4, the differential pressure of oil through each damping hole is: $\Delta P_{2}=\Delta P$ $\Delta P_{3}=P_{L S}-P_{T} \quad \Delta P_{4}=P_{L S}-P_{H 1} \quad \Delta P_{5}=P_{H 2}-P_{F D}$, 
$\Delta P_{6}=P-P_{F D} \quad \Delta P_{7}=P_{F D}-P_{L} \quad \Delta P_{L-R}=\Delta P_{8}=P_{L}-P_{R}$ $\Delta P_{9}=P_{R}-P_{T}$,

The flow rate-pressure relationship of the redirector can be transformed into

$$
\begin{gathered}
P=\frac{\rho}{2}\left(\frac{q_{m}}{C_{d}}\right)^{2}\left(\frac{1}{\left(A_{4}\left(x_{z}\right)\right)^{2}}+\frac{1}{\left(A_{1}\left(x_{z}\right)\right)^{2}}+\frac{1}{\left(A_{5}\left(x_{z}\right)\right)^{2}}\right)+\frac{T_{l}}{D_{m}} \\
+\frac{\rho}{2}\left(\frac{q_{m}+q_{6}}{C_{d}}\right)^{2}\left(\frac{1}{\left(A_{7}\left(x_{z}\right)\right)^{2}}+\frac{1}{\left(A_{9}\left(x_{z}\right)\right)^{2}}+\frac{1}{\left(A_{8}\left(x_{z}\right)+A_{z}\right)^{2}}\right)+P_{T}, \\
q_{6}^{2}=\left(\left(\frac{A_{6}\left(x_{z}\right)}{A_{1}\left(x_{z}\right)}\right)^{2}+\left(\frac{A_{6}\left(x_{z}\right)}{A_{4}\left(x_{z}\right)}\right)^{2}+\left(\frac{A_{6}\left(x_{z}\right)}{A_{5}\left(x_{z}\right)}\right)^{2}\right) q_{m}{ }^{2} \\
+\frac{2 T_{l}}{\rho D_{m}}\left(C_{d}\right)^{2}\left(A_{6}\left(x_{z}\right)\right)^{2}
\end{gathered}
$$

\section{Simulation Method and Related Settings}

\subsection{Simulation Method}

As shown in Figure 2, all the circumferential movements of the redirector are converted into translational movements. To simplify model structure, the metering motor is replaced by a meter cylinder with an inlet and an outlet replacing seven closed chambers and only six inlet holes are considered for translation in the same direction. In addition, the seven holes of the valve body corresponding to port $\mathrm{H}$ and the metering motor are equivalent to an inlet and a return port. The magnitude of the input force signal in the model represents the rotation speed of the steering wheel. The pressure regulating valve as equivalent load instead of the steering load. The model is established in accordance with the 7 oil circuit modules in Section 3.

\begin{tabular}{|c|c|c|c|c|c|}
\hline Definition & Item & Value & Definition & Item & Value \\
\hline \multirow{5}{*}{$\begin{array}{l}\text { Priority } \\
\text { valve }\end{array}$} & $d_{\text {spool }}$ & $25 \mathrm{~mm}$ & \multirow{4}{*}{ Redirector } & $d_{\text {spool }}$ & $10 \mathrm{~mm}$ \\
\hline & $d_{\text {rod }}$ & $14 \mathrm{~mm}$ & & $d_{\text {rod }}$ & $5 \mathrm{~mm}$ \\
\hline & $m$ & $0.3 \mathrm{~kg}$ & & $m_{1}$ & $0.284 \mathrm{~kg}$ \\
\hline & $F_{0 k}$ & $458.8 \mathrm{~N}$ & & $m_{2}$ & $0.301 \mathrm{~kg}$ \\
\hline & $k$ & $28.3 \mathrm{~N} / \mathrm{mm}$ & Metering & $m_{0}$ & $0.6 \mathrm{~kg}$ \\
\hline Pump & $Q_{t}$ & $80 \mathrm{cc} / \mathrm{rev}$ & motor & $d_{\text {piston }}$ & $79.6 \mathrm{~mm}$ \\
\hline Signal & $F(x)$ & $0.001675 x$ & oil & $\rho$ & $850 \mathrm{~kg} / \mathrm{m}^{3}$ \\
\hline
\end{tabular}

Figure 5 shows the simulation model of the redirector.

\subsection{Simulation General Setting}

Table 1 Key parameters of the simulation model

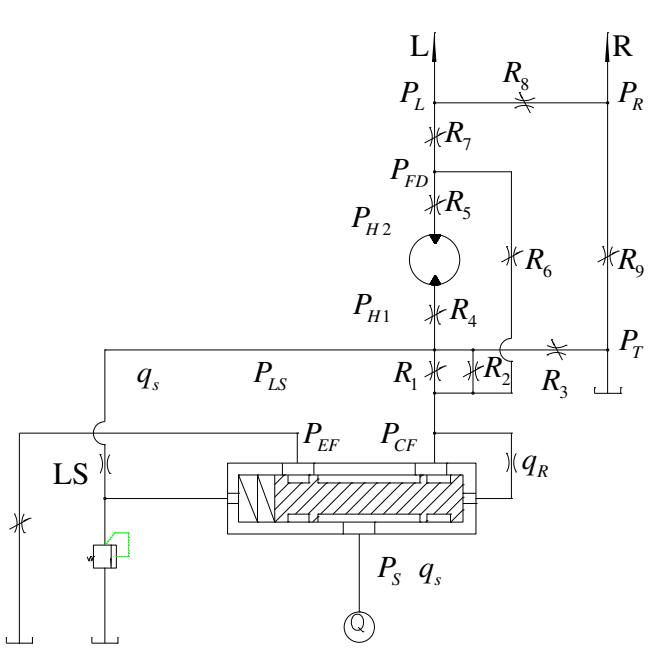

Figure 4 Schematic diagram of the equivalent damping

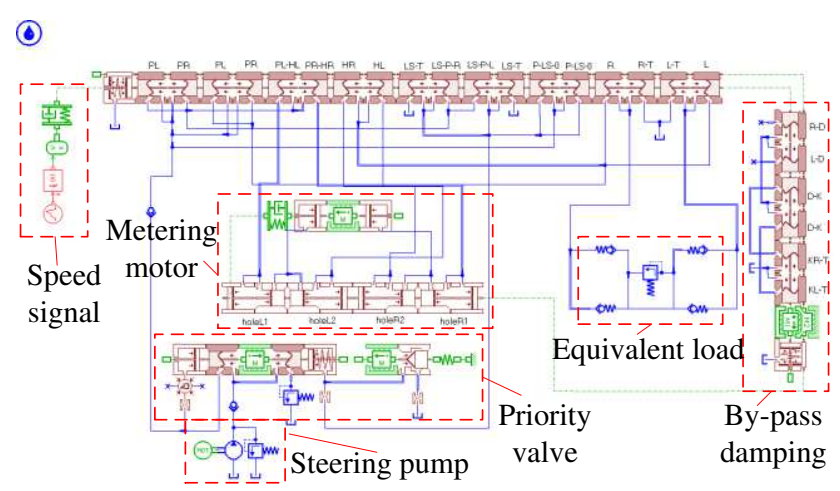

Figure 5 Simulation model of the novel redirector.

The main parameters of the simulation model are given in Table 1. The hydraulic pressure acting on the control spool can be offset, so the acting area of the two relative valve blocks should be kept equal, and all parameters of the valve port area must be consistent. According to Equations (1) (9), the opening area formed by the relative movement of the control spool and control sleeve is set. When the metering cylinder is used to replace the metering motor, the measuring area of the cylinder is calculated by the displacement of the motor.

$$
d=\frac{4 V}{\pi D^{2}}
$$

The speed signal of the steering wheel is converted to the speed of translation

$$
v=2 \pi r n
$$

\subsection{Validation of the Model}

To verify whether the simulation model can well reflect the working principle and dynamic performance of the actual structure, the performance of the redirector with by-pass 


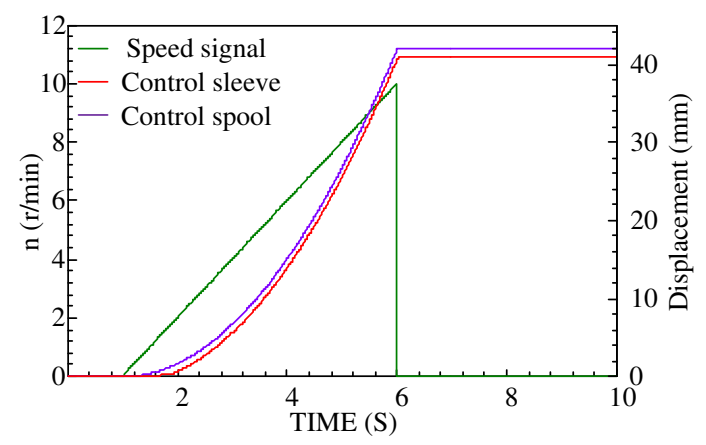

Figure 6 Displacement of control spool and sleeve.

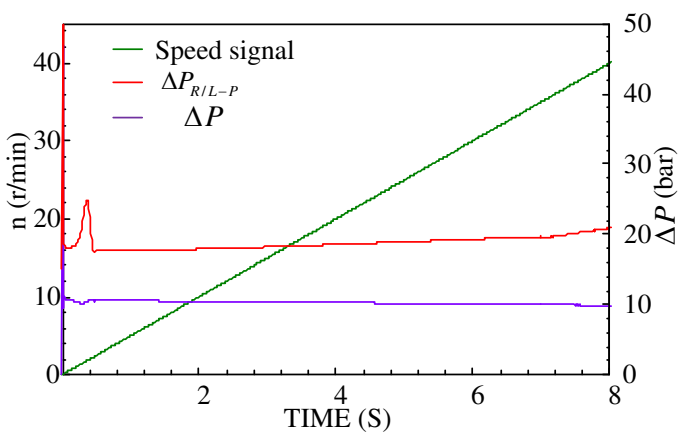

Figure 7 Relation between speed signal and $\Delta P, \Delta P_{R / L-P}$.

damping under different working conditions is simulated and analyzed. Figure 6 is the displacement curve of the control spool and control sleeve under the certain rotating speed signal. It can be seen from the curve that the control spool begins to move immediately when the force signal is applied. The control sleeve does not move at the beginning due to the dead zone between the control spool and control sleeve. When the rotation speed increases and the port $\mathrm{P}$ is opened, the opening area and the displacement difference between the control spool and control sleeve increase. When the rotation speed is 0 , the opening area is reduced to close and the control sleeve has a slight lag in stop movement relative to the control spool. The simulation results show that the control spool and control sleeve of the redirector ensure good follow-up performance when the steering wheel speed increases.

Figure 7 shows the differential pressure $\Delta P$ and the pressure loss $\Delta P_{R / L-P}$ of the redirector under the constant increase speed signal. It can be seen from curves that $\Delta P_{R / L-P}$ gradually increases with the increase of the redirector opening area, while $\Delta P$ remains at a constant value. The overflow area and flow rate of the redirector with the increase of the steering wheel rotating speed. However, $\Delta P_{R / L-P}$ increases with the overflow area increasing, because the overflow area gradient of each orifice is smaller than that of the flow rate.
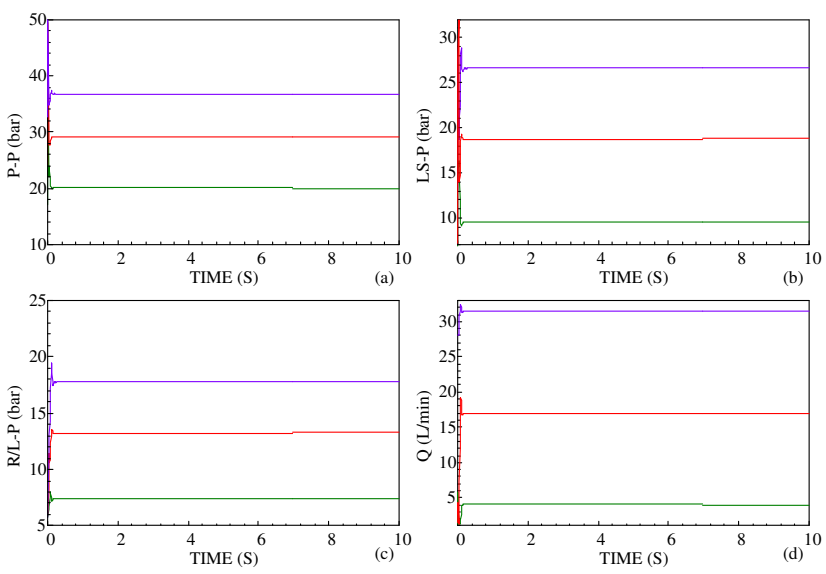

Figure 8 Simulation results under no-load condition of electromotor speed is $708 \mathrm{r} / \mathrm{min}$. (a) $P$; (b) $P_{L S}$; (c) $P_{R / L}$; (d) $Q$
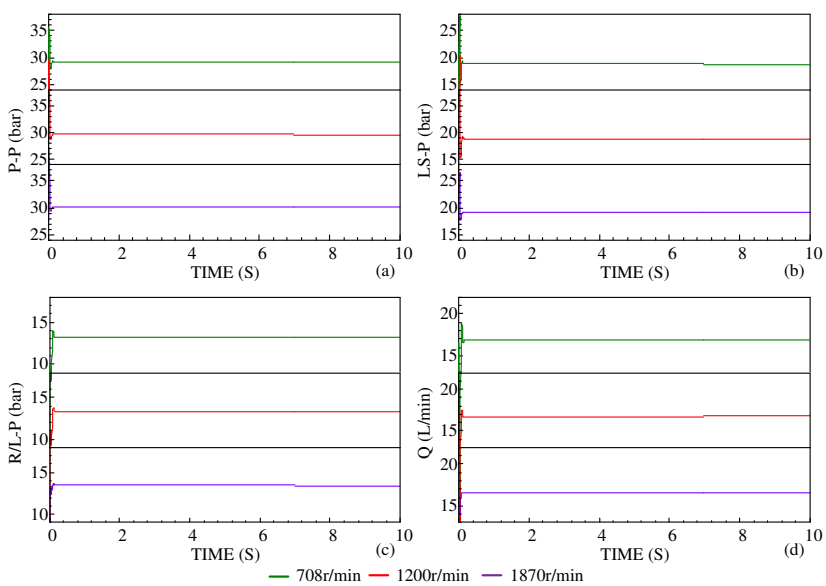

Figure 9 Simulation results under no-load condition of steering wheel speed is $20 \mathrm{r} / \mathrm{min}$. (a) $P$; (b) $P_{L S}$; (c) $P_{R / L}$; (d) $Q$
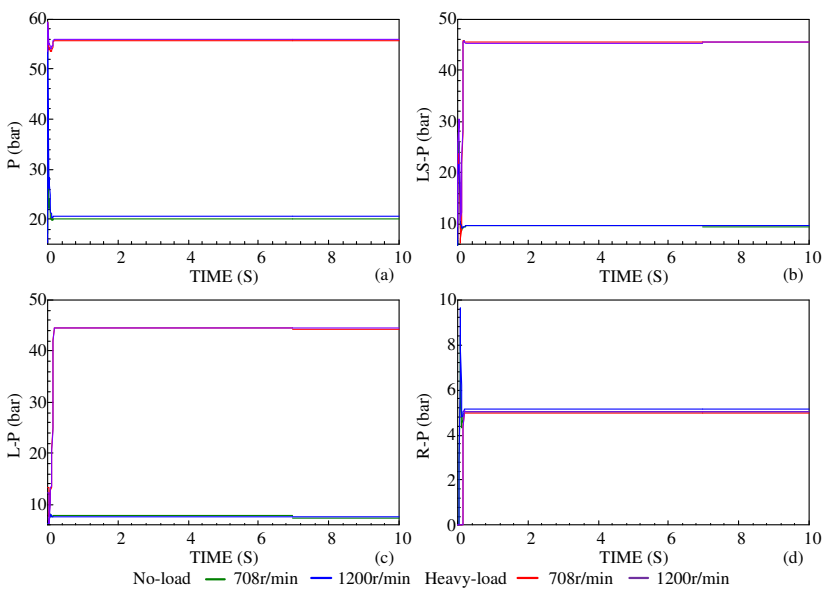

Figure 10 Simulation results under steering wheel speed $8 \mathrm{r} / \mathrm{min}$, electromotor speed is $708 \mathrm{r} / \mathrm{min}$. (a) $P$; (b) $P_{L S}$; (c) $P_{L}$; (d) $P_{R}$

Based on the simulation results, the model completely 


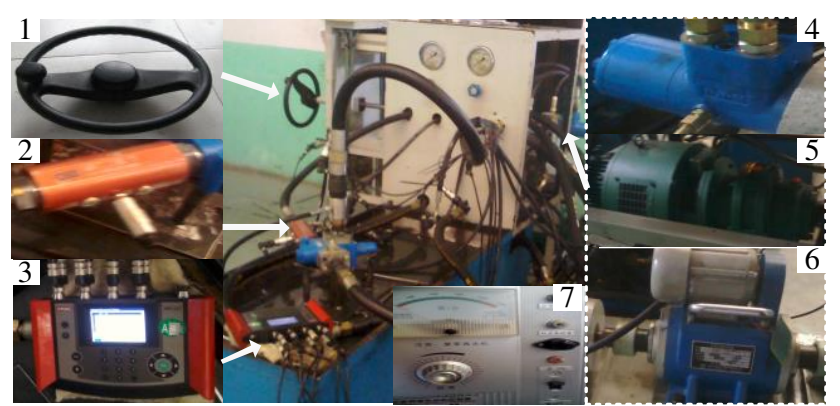

Figure 11 Photograph of the redirector experiment platform. 1. Steering wheel; 2.Pressure sensor; 3. Data acquisition; 4. Redirector; 5. Pump; 6. Electromotor; 7. Controller.

Table 2 Main parameters and size of the experiment platform

\begin{tabular}{ll}
\hline \multicolumn{1}{c}{ Definition } & \multicolumn{1}{c}{ Parameters } \\
\hline Pump & Displacement:80cc/rev, Max. rotation speed 2350rmp; \\
Data acquisition & Signal:1-5V, Accuracy: 0.02\%, Channl:16; \\
Pressure sensor & Range:0-600bar, Accuracy: 0.5\%, Voltage:12VDC; \\
Flow meter & Range:300L/min, Accuracy: 1\%; \\
Tachometer & Range:0-3000r/min, Accuracy: $1 \% ;$ \\
\hline
\end{tabular}

represents to the actual structure of the redirector, which can reflect the working principle and have good follow characteristics.

\subsection{Simulation Results}

The dynamic characteristics of the redirector with by-pass damping are analyzed from three aspects: different steering wheel speed, different electromotor speed and different steering load. Figure 8 shows the simulation results of the redirector under different steering wheel speeds with no-load condition of electromotor speed is $708 \mathrm{r} / \mathrm{min}$. It can be seen from the simulation curves that that the flow rate into the redirector increases with the increase of the steering wheel speed. The flow rate has a linear relationship with the opening area $A_{1}$ when $\Delta P$ remains stable, the redirector has good operating performance. The flow amplification holes are opened wen the rotation speed is $20 \mathrm{r} / \mathrm{min}$ and $30 \mathrm{r} / \mathrm{min}$, and the flow rate increases rapidly. Besides, this part of the flow rate directly reaches outlet of the redirector without passing through the metering motor.

Figure 9 shows the simulation results of the redirector under different electromotor speeds with no-load condition of steering wheel speed is $20 \mathrm{r} / \mathrm{min}$. Change the electromotor speed, the flow rate into the redirector and the pressure of ports $\mathrm{P}, \mathrm{LS}, \mathrm{L} / \mathrm{R}$ remain constant. This shows that the flow rate required by the steering system is constant and not affected by the electromotor speed when the steering wheel speed is fixed.

Figure 10 shows the simulation results under no-load and heavy-load conditions with the steering wheel speed and electromotor speed are fixed. The output pressure and pressure shock of the redirector under heavy-load condition are higher than that of no-load, and the oil return pressure in both cases is the same. The output pressure and pressure fluctuation of the steering gear under heavy load are higher than that of no load, and the oil return pressure is the same in both cases. According to the analysis of simulation results, the change of load has no effect on the flow rate and differential pressure of the redirector with the same steering speed.

It can be seen from Figure10 that input the step signal, the rise time under no-load condition is $0.23 \mathrm{~s}$, which is shorter than $0.49 \mathrm{~s}$ under heavy-load condition. The steering system response becomes slower when the load gets heavy.

\section{Experiment of the Redirector}

\subsection{Simulation Experiment Platform}

Although the simulation model has been set according to the actual structural parameters, the influence of pipeline has been ignored. Therefore, it is necessary to verify the correctness of the equivalent load and the model by experiments. According to the simulation system model in Figure 5, the simulation experiment platform of by-pass damping redirector is established, as shown in Figure 11. When assembling the platform, the bending degree of pipelines should be reduced as much as possible to reduce the influence of pressure loss on the measured data. Sensors should be installed as close to the pressure point as possible. In the experiment, the angular velocity of the steering wheel is collected by a speed measuring instrument. Pressure sensors are used to collect pressure of the hydraulic pump, the inlet and outlet of the redirector and the port LS. Flow meters are used to collect the flow rate of the redirector inlet and outlet. The experimental instruments required are given in Table 2.

\subsection{Experimental Results}

Three steering conditions with different steering wheel speed, different electromotor speed and different steering load were used to test and analyze the performance of the redirector with by-pass damping. The steering condition in the experiment is consistent with the simulation steering condition to ensure the accuracy of the experiment result. Figure 12 shows the experimental results of redirector with by-pass damping under the no-load condition with the electromotor speed is $708 \mathrm{r} / \mathrm{min}$ when the steering wheel speed is $8 \mathrm{r} / \mathrm{min}, 20 \mathrm{r} / \mathrm{min}$, and $30 \mathrm{r} / \mathrm{min}$, respectively. It can be seen that when the steering wheel speed increases, the flow rate through the redirector increases, resulting in the increase of pressure at port LS and port L/R. 

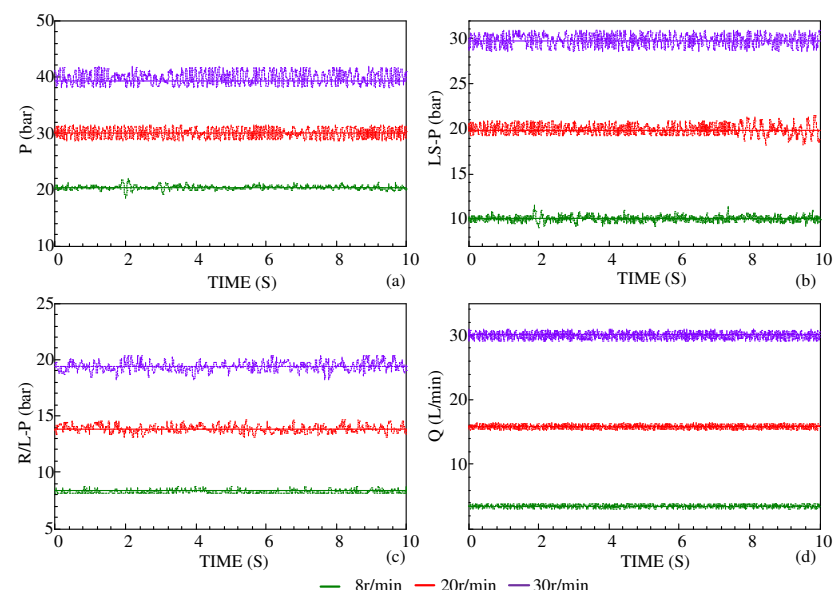

Figure 12 Experimental results under no-load condition of electromotor speed is $708 \mathrm{r} / \mathrm{min}$. (a) $P$; (b) $P_{L S}$; (c) $P_{R / L}$; (d) $Q$
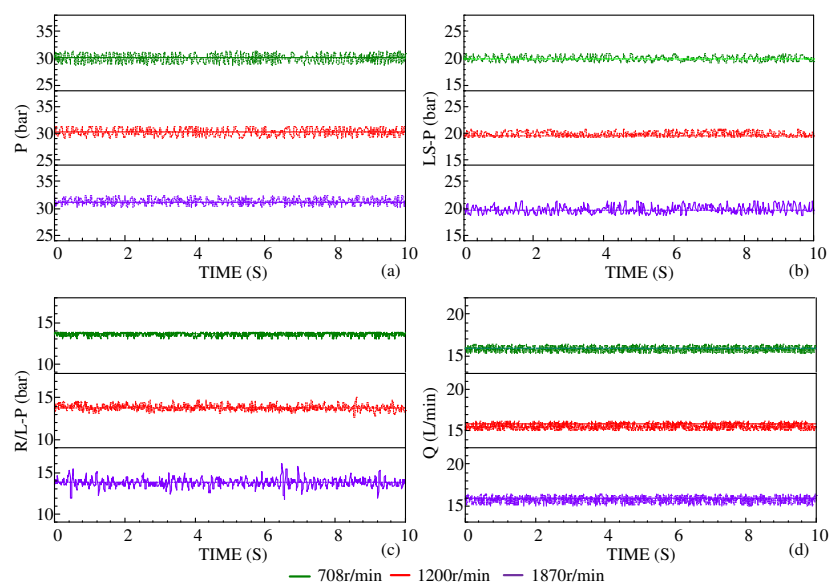

Figure 13 Experimental results under no-load condition of steering wheel speed is $20 \mathrm{r} / \mathrm{min}$. (a) $P$; (b) $P_{L S}$; (c) $P_{R / L}$; (d) $Q$
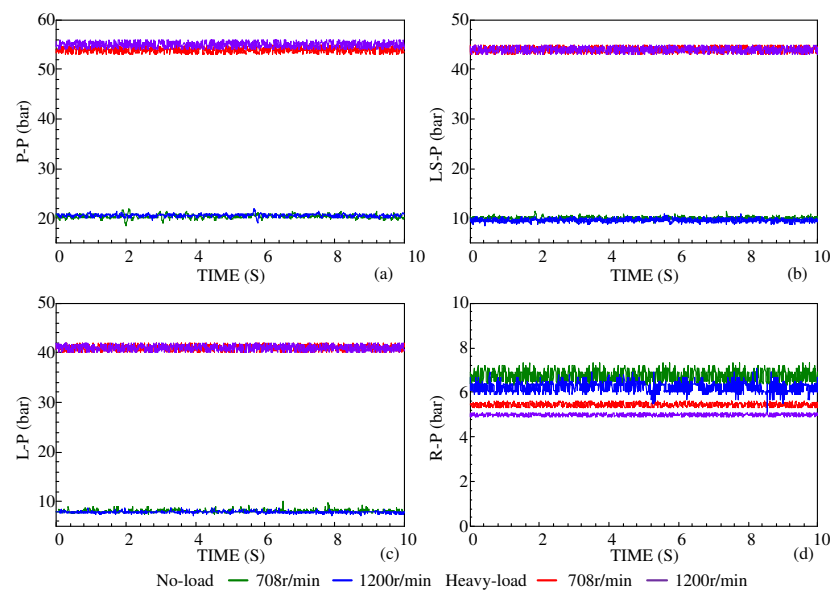

Figure 14 Experimental results under steering wheel speed $8 \mathrm{r} / \mathrm{min}$, electromotor speed is $708 \mathrm{r} / \mathrm{min}$. (a) $P$; (b) $P_{L S}$; (c) $P_{L}$; (d) $P_{R}$

The steering wheel speed is the main factor that affects the flow rate of the steering system. When the speed is higher, the inlet flow rate of the redirector changes more obviously with the increase of steering wheel speed.

Figure 13 shows the experimental results under the no-load condition with the steering wheel speed is $20 \mathrm{r} / \mathrm{min}$ when the electromotor speed is $708 \mathrm{r} / \mathrm{min}, 1200 \mathrm{r} / \mathrm{min}$, and $1870 \mathrm{r} / \mathrm{min}$, respectively. It can be seen from curves that when the electromotor speed increases, the flow rate through the redirector and the pressure at port P, port LS, port $\mathrm{R} / \mathrm{L}$ are basically constant. It can be concluded that the required flow rate of the steering system is determined by the steering wheel speed rather than the electromotor speed.

Figure 14 shows the experimental results under no-load and heavy-load conditions with the steering speed is $8 \mathrm{r} / \mathrm{min}$, and the electromotor speed is $708 \mathrm{r} / \mathrm{min}, 1200 \mathrm{r} / \mathrm{min}$, respectively. The pressure at port $\mathrm{P}$, port $\mathrm{LS}$ and port $\mathrm{R} / \mathrm{L}$ increases significantly with the increase of steering load, while the pressure variation of port $\mathrm{R}$ is not obvious. Combined with the previous simulation analysis, the pressure of steering system increases, and the response slows down when the steering load increases.

Part of the simulation and experiment results are shown in Table 3, the maximum error is $11.1 \%$, which proves that the simulation model has good accuracy. The model can be used to further analyze the steering performance.

Table 3 Part of the simulation and experimental results

\begin{tabular}{llllll}
\hline $\begin{array}{c}\text { Working } \\
\text { condition }\end{array}$ & Category & $\begin{array}{c}P \\
(\mathrm{~b} a r)\end{array}$ & $\begin{array}{c}P_{L S} \\
(\mathrm{~b} a r)\end{array}$ & $\begin{array}{c}P_{R / L} \\
(\mathrm{bar})\end{array}$ & $\begin{array}{c}Q \\
(\mathrm{~L} / \mathrm{min})\end{array}$ \\
\hline 708r/min & Simulation & 20.05 & 9.51 & 7.45 & 4 \\
$8 \mathrm{r} / \mathrm{min}$ & Experiment & 20.38 & 10 & 8.34 & 3.6 \\
No-load & Error & $1.6 \%$ & $4.9 \%$ & $10.6 \%$ & $11.1 \%$ \\
\hline 708r/min & Simulation & 36.8 & 26.61 & 17.75 & 31.53 \\
30r/min & Experiment & 39.38 & 29.72 & 19.34 & 30.22 \\
No-load & Error & $6.5 \%$ & $10.4 \%$ & $8.2 \%$ & $4.3 \%$ \\
\hline 1200r/min & Simulation & 29.63 & 18.91 & 13.33 & 16.91 \\
20r/min & Experiment & 30.19 & 19.47 & 13.6 & 15.86 \\
No-load & Error & $1.8 \%$ & $2.9 \%$ & $0.5 \%$ & $6.6 \%$ \\
\hline 1870r/min & Simulation & 30.2 & 19.06 & 13.44 & 16.56 \\
20r/min & Experiment & 31.2 & 19.7 & 13.8 & 15.97 \\
No-load & Error & $3.2 \%$ & $3.2 \%$ & $2.6 \%$ & $3.7 \%$ \\
\hline & & & & &
\end{tabular}

\section{Analysis of Dynamic Characteristics and Oscillation}

According to the force equation and flow continuity equation of the redirector and steering load during the steering process 


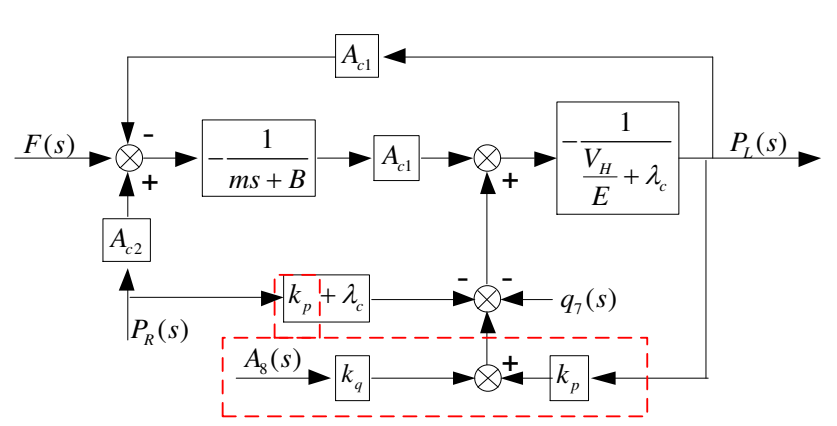

Figure 15 The schematic of redirector mathematical model

$$
\begin{gathered}
A_{L} P_{L}-A_{R} P_{R}=m \frac{d u}{d t}+B u(t)+F(t) \\
q_{L-R}(t)=A_{L} u(t)+\frac{V}{E} \frac{d P_{L}(t)}{d t}+\lambda_{c}\left[P_{L}(t)-P_{R}(t)\right]
\end{gathered}
$$

where $V$ is the chamber volume of the equivalent load, $E$ is the effective bulk modulus of oil, $F$ is the external load, $u(t)$ is the speed of the equivalent load response, $B$ is the viscous damping, $\lambda_{c}$ is the leakage coefficient of the equivalent load.

The redirector with by-pass damping has the pressure-flow rate linearization equation of steering load

$$
q_{8}=q_{7}-q_{L-R}=K_{q} A_{8}(s)+K_{c}\left(P_{L}-P_{R}\right) \text {, }
$$

$$
\text { where } K_{q}=\frac{\partial q_{8}}{\partial x}=C_{d} \sqrt{2 \frac{P_{L}-P_{R}}{\rho}} \quad K_{\mathrm{c}}=\frac{\partial q_{8}}{\partial P_{L}}=\frac{C_{d} A_{8}}{\sqrt{2 \rho\left(P_{L}-P_{R}\right)}}
$$

Dynamic characteristics block diagram of the two redirector structures is obtained by Laplace transformation, as shown in Figure 15. Variables inside the dotted line is the influence of the by-pass damping structure.

If the right outlet pressure $P_{R}(s)=0$, the flow rate $q_{7}(\mathrm{~s})=0$, the dynamic transfer function with the load as the input and left outlet pressure as the output can be obtained

$$
\frac{P_{L}(s)}{F(s)}=\frac{\frac{A_{L} E}{m V}}{s^{2}+\left(\frac{\lambda_{c} E}{V}+\frac{B}{m}\right) s+\frac{B \lambda_{c}+A_{L}^{2}}{m V} E}=\frac{K_{A 1} \omega_{n 1}^{2}}{s^{2}+2 \xi_{1} \omega_{n 1} s+\omega_{n 1}^{2}}
$$

Combining equations (23), (24), and (25), the dynamic transfer function of the redirector with by-pass damping is obtained

$$
\begin{aligned}
& \frac{P_{L}(s)}{F(s)}=\frac{\frac{A_{L} E}{m V}}{s^{2}+\left(\frac{E\left(\lambda_{c}+K_{c}\right)}{V}+\frac{B}{m}\right) s+\frac{\left(\lambda_{c}+K_{c}\right) B+A_{L}^{2}}{m V} E} \\
& =\frac{K_{A 2} \omega_{n 2}^{2}}{s^{2}+2 \xi_{2} \omega_{n 2} s+\omega_{n 2}^{2}}
\end{aligned},
$$

Gains of the two structure redirectors are

$$
\begin{gathered}
K_{A 1}=\frac{A_{L}}{B \lambda_{c}+A_{L}{ }^{2}}, \\
K_{A 2}=\frac{A_{L}}{\left(\lambda_{c}+K_{c}\right) B+A_{L}^{2}},
\end{gathered}
$$

Undamped natural frequencies are

$$
\begin{gathered}
\omega_{n 1}=\sqrt{\frac{E}{m V}\left(B \lambda_{c}+A_{L}^{2}\right)}, \\
\omega_{n 2}=\sqrt{\frac{E}{m V}\left(B \lambda_{c}+B K_{c}+A_{L}^{2}\right)},
\end{gathered}
$$

System damping ratios are

$$
\begin{gathered}
\xi_{1}=\frac{\omega_{n 1}}{2 A_{L}^{2}}\left(m \lambda_{c}+\frac{B V}{E}\right), \\
\xi_{2}=\frac{\omega_{n 2}}{2 A_{L}^{2}}\left(m \lambda_{c}+m K_{c}+\frac{B V}{E}\right),
\end{gathered}
$$

Outlet characteristic equations of the two structure redirectors are as follows

$$
\begin{gathered}
s^{2}+\left(\frac{\lambda_{c} E}{V}+\frac{B}{m}\right) s+\frac{E}{m V}\left(B \lambda_{c}+A_{L}^{2}\right)=0 \\
s^{2}+\left(\frac{\left(\lambda_{c}+K_{c}\right) E}{V}+\frac{B}{m}\right) s+\frac{E}{m V}\left(B \lambda_{c}+B K_{c}+A_{L}^{2}\right)=0
\end{gathered}
$$

The pressure overshoot is

$$
M_{p n}=e^{-\frac{\xi_{n} \pi}{\sqrt{1-\xi_{n}^{2}}}}
$$




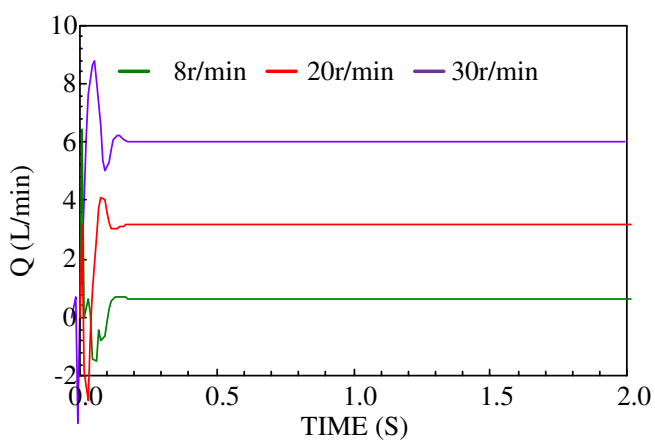

Figure 16 Flow rate through by-pass orifices.

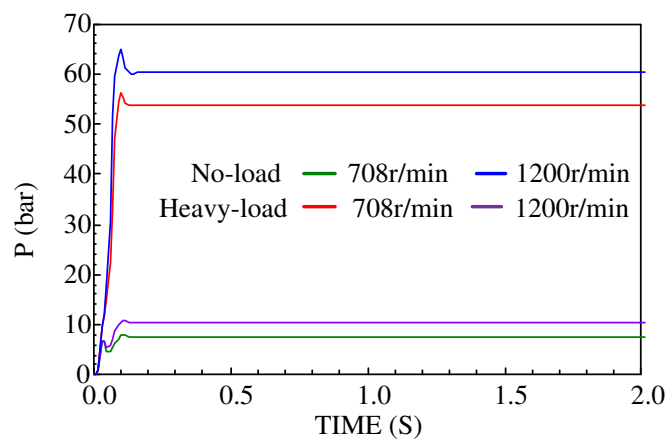

Figure 17 Pressure of the equivalent load inlet.

According to the Routh-Hurwitz stability criterion, it is known that both systems formed by the two redirectors are stable.

Based on above equations, when the steering load $F$ increases, $P_{L}$ increases, $\mathrm{K}_{\mathrm{c}}$ decreases, $\omega_{n}, \xi$ will decrease and the pressure overshoot $M_{p}$ will increase. The number of system oscillations increases, the stability decreases, and the adjustment time increases. Therefore, the sudden increase of the steering load will lead to the system oscillation. If the opening area $A_{8}$ of the orifice $R_{8}$ increases, $\mathrm{K}_{\mathrm{c}}$,increases, $\xi$ will increase and the pressure overshoot $M_{p}$ will decrease. the number of oscillations will decrease, and the corresponding stability of the system will increase. In this study, $\xi_{1}<\xi_{2}$, $M_{P 1}>M_{P 2}$, and the overshoot of the redirector with by-pass damping is relatively small.

The severity of system oscillation will be determined by the damping ratio $\xi$. The smaller $\xi$, the more severe the oscillation. The decay speed of the oscillation process is determined by $\left|\xi \omega_{n}\right|$. The larger $\left|\xi \omega_{n}\right|$, the faster the decay will be. According to the above analysis

$$
\left|\xi \omega_{n}\right|_{1}<\left|\xi \omega_{n}\right|_{2}
$$

Therefore, compared with the original redirector, the output pressure oscillation decays more quickly and the system is more stable when a step signal is input to the redirector with by-pass damping.

Figure 16 shows the flow rate curve through the by-pass loop under different steering wheel speeds of no-load condition with electromotor speed is $708 \mathrm{r} / \mathrm{min}$. The by-pass loop flow rate is $0.66 \mathrm{~L} / \mathrm{min}, 3.15 \mathrm{~L} / \mathrm{min}, 6.03 \mathrm{~L} / \mathrm{min}$ when the steering wheel speed is $8 \mathrm{r} / \mathrm{min}, 20 \mathrm{r} / \mathrm{min}, 30 \mathrm{r} / \mathrm{min}$, respectively. Accounting for $16.5 \%, 18.6 \%$ and $19.1 \%$ of the total flow rate into the redirector, respectively. The simulation results prove that the flow rate through by-pass loop increases with the increase of steering wheel speed, but the increase rate decreases. The proportion of flow rate through by-pass loop is relatively stable.

Figure 17 shows the equivalent load inlet pressure simulation curves of the two redirectors under no-load and heavy-load conditions with electromotor speed is 708 $\mathrm{r} / \mathrm{min}$. Under no-load condition and the steering wheel speed is $20 \mathrm{r} / \mathrm{min}$, compared with the original redirector, the equivalent load inlet pressure overshoot of the redirector with by-pass damping reduces from 8.6bar to 7.9bar. Under heavy-load condition, the pressure overshoot reduces from $65.04 \mathrm{bar}$ to $56.35 \mathrm{bar}$, with a decrease rate of $13.4 \%$. The pressure oscillation duration is reduced from $2.09 \mathrm{~s}$ to $1.6 \mathrm{~s}$, with a decrease rate of $23.4 \%$. The research work in this paper can make a certain contribution to the stability optimization of articulated vehicle steering technology.

\section{Conclusions}

In this paper, to reduce the pressure oscillation and enhance the stability of the articulated vehicle steering system, a novel redirector with by-pass damping is proposed. The steering load is equivalent replaced to make the research conditions more convenient control. Through the simulation and experimental research and analysis of the novel redirector under different working conditions, the following conclusions can be concluded:

(1) For the redirector with by-pass damping, the peak value of the equivalent load inlet pressure is reduced from 65.04bar to 56.35bar under heavy-load condition during steering. Compared with the original redirector, the overshoot is reduced by $13.4 \%$, which reduces the number of system oscillations.

(2) Compared with the original redirector, the output pressure oscillation duration caused by the load change of the redirector with by-pass damping is reduced by $23.4 \%$. The pressure oscillation decays faster, and the 
system is more stable.

(3) For the redirector with by-pass damping, the flow rate through by-pass loop increases with the increase of steering wheel speed, but the increase rate decreases. The proportion of flow rate through by-pass loop is relatively stable. Therefore, the by-pass damping structure has little effect on the supply of flow rate during steering.

\section{Declaration}

\section{Availability of data and materials}

The datasets supporting the conclusions of this article are included within the article.

\section{Competing interests}

The authors declare no competing financial interests.

\section{Funding}

Supported by National Key Research and Development Program of China, (Grant No.2018YFB2000900).

\section{Authors' contributions}

The author' contributions are as follows: XH Liu, JS Chen conceived the idea of the study; YQ Wang, DY Huo performed the theoretical derivation and simulation experiment. FY contributed to structure design. YQ Wang analyzed the data and wrote the manuscript. All authors read and approved the final manuscript.

\section{Acknowledgements}

The authors sincerely thanks to Professor Tongjian Wang of Jilin University for his critical discussion and reading during manuscript preparation.

\section{Author Details}

School of Mechanical and Aerospace Engineering, Jilin University, Jinlin 130022, China.

\section{References}

[1] Yan X , Yang J , Quan L . Co-simulation and experiment of wheel loader during operation process. Transactions of the Chinese Society of Agricultural Engineering, 2015, 31(16):102-109.

[2] Wang, X., Yang, J., Quan, L., Zhang, X., \& Wang, J. A novel high-efficiency wheel loader power steering system with fault-tolerant capability. IEEE Transactions on Vehicular Technology, 2018, 67(10), 9273-9283.

[3] Meng, Z., \& Zang, H. Analysis of hydraulic steering system of tracked all-terrain vehicles' articulated mechanism. AIP Conference Proceedings, 2018, 1955(1): 030003-1-030003-7.

[4] Xu, T., Shen, Y., Huang, Y., \& Khajepour, A. Study of hydraulic steering process for articulated heavy vehicles based on the principle of the least resistance. IEEE/ASME Transactions on Mechatronics, 2019, 24(4), 1662-1673.

[5] Zardin, B., Borghi, M., Gherardini, F., \& Zanasi, N. Modelling and simulation of a hydrostatic steering system for agricultural tractors. Energies, 2018, 11(1), 230.

[6] Lei, D., Kaiping, D., \& You-ping, G. The optimum design for pivot points of steering mechanism on HT25J wheel loader. 2011 International Conference on Consumer Electronics, Communications and Networks (CECNet), Xianning, China, April 16-28, 2011: 2760-2763.

[7] Wang tongjian, Chen jinshi, et al. Combined simulation and test of hydraulic steering system. Journal of jilin university (engineering science edition), 2013,43 (03) : 607-612. (in Chinese)

[8] Wang, C., Zhang, Y., \& Zhao, W. Multi-objective optimization of a steering system considering steering modality. Advances in Engineering Software, 2018, 126, 61-74. doi:10.1016/j.advengsoft.2018.09.012

[9] KITAHARA, K., KAZAMA, K., \& MOURI, H. Design of a new steering system to solve the problem of steering operation during low speed driving. Mechanical Engineering Journal, 2019, 6(3), 18-00386-18-00386. doi:10.1299/mej.18-00386

[10]Yin, Y., Rakheja, S., Yang, J., \& Boileau, P. Design optimization of an articulated frame steering system. Proceedings of the Institution of Mechanical Engineers, Part D: Journal of Automobile Engineering, 2018, 232(10), 1339-1352. doi: $10.1177 / 0954407017729052$

[11]Cao, B., Liu, X., Chen, W., Zhang, Y., \& Li, A. Depth optimization analysis of articulated steering hinge position based on genetic algorithm. Algorithms, 2019, 12(3), 55. doi:10.3390/a12030055

[12]AMICO D A. Pressure control in hydraulic power steering systems: division of fluid and mechatronic systems. Sweden: Linköping University. Department of Management and Engineering, 2013: 14-22.

[13]Haggag, S., Alstrom, D., Cetinkunt, S., \& Egelja, A. Modeling, control, and validation of an electro-hydraulic steer-by-wire system for articulated vehicle applications. IEEE/ASME Transactions on $\begin{array}{lll}\text { Mechatronics, } & \text { 2005, } & \text { 68(6), }\end{array}$ doi:10.1109/TMECH.2005.859838

[14]K. Heybroek, Saving Energy in Construction Machinery using Displacement Control Hydraulics. Linköping, Sweden: Linköping University., 2008.

[15]K. Heybroek et al., Evaluating a pump controlled open-circuit solution, 51st National Conference on Fluid Power, Las V egas, USA, 2008: 681-694.

[16]K. Heybroek, J. Larsson, and J. O. Palmberg, Mode Switching and Energy Recuperation in Open-Circuit Pump Control. Tampere, Finland: Tampere Univ. Technol., 2009: 197-209.

[17]K. Heybroek, J. O. Palmberg, and J. Larsson, Open circuit solution for pump controlled actuators, 4th FPNI-PhD Symp., Sarasota, FL, USA, 2008: 27-40.

[18]Daher, N., \& Ivantysynova, M. Energy analysis of an original steering technology that saves fuel and boosts efficiency. Energy Conversion and Management, 2014, 86, 1059-1068. doi:10.1016/j.enconman.2014.06.073

[19]Daher, N. A., \& Ivantysynova, M. Pump controlled steer-by-wire system. SAE Technical Papers, 2013, 7 doi:10.4271/2013-01-2349

[20]Naseem Daher, Chuang Wang, \& Monika Ivantysynova. Novel Energy-Saving Steer-by-Wire System for Articulated Steering Vehicles: A Compact Wheel Loader Case Study. 13th scandinavian 
international conference on fluid power, linköping, Sweden, June 3-5, 2013. doi:10.3384/ecp1392a54

[21]Daher, N. New Steering Concept for Wheel Loaders. The 9th International Fluid Power Conference, Aachen, Germany, March 24-26, 2014.

[22]G. P . Massarotti et al., Hydrostatic steering system and energy saving evaluation in idle regime. 10th JFPS International Symposium on Fluid Power, Fukuoka, Octorber 24-27, 2017:2A11-1-2A11-7.

[23] Wang JH, Sun CL, et al. Load sensing steering hydraulic system for loading machine. Chinese patent CN202272517U, June, 2012.

[24]DellAmico, A., Krus, P., et al. Modeling, simulation, and experimental investigation of an electrohydraulic closed-center power steering system. IEEE/ASME Transactions on Mechatronics, 2015, 20(5), 2452-2462. doi:10.1109/TMECH.2014.2384005

[25]Huang HT, Li JN, Zhuo JW, et al. Improved structure of hydraulic system of loader. Chinese patent CN201891142U, July 6, 2011.

[26]Tomiyoshi, Yasumasa, \& Nozawa, Toshiro. Hydraulic steering system for articulated vehicle. US5269389 A, 1993.

[27]Chai XJ, Hou HG, Yang ZY. Full-hydraulic steering gear capable of eliminating entrap phenomenon. Chinese patent CN2753893, Jan 25, 2005.

[28]Ji H, Tan ZS, Wei LJ, Zhang W. Steering preference type flux amplification valve. Chinese patent CN101255879, Sept 3, 2008.

[29]Ren DM, Liu GW, Fan XT, Song YL, Ma PP. Steering shake preventing device of loading machine. Chinese patent CN203402236U, Jan 22, 2014.

[30]Lu qianqian. Simulation analysis and test of full hydraulic steering system for flow amplification. Hangzhou:Zhejiang university, 2010.

[31]Liu xinhui, li qianwen, Chen jinshi, et al. Mathematical modeling and simulation of load - sensing priority valve. Journal of jilin university (engineering \& engineering edition), 2015, 045 (006): $1817-1824$

[32]Wang gang. Characteristics of coaxial flow amplification full hydraulic steering system. Changchun:Jilin university, 2014.

\section{Biographical notes}

Yu-Qi Wang, born in 1993, is currently a PhD candidate at School of Mechanical and Aerospace Engineering, Jilin University, China She received bachelor's degree from Jilin University, China, in 2016. Her research interests include fluid power transmission and control.

Xin-Hui Liu, born in 1962, is currently a professor at School of Mechanical and Aerospace Engineering, Jilin University, China.

Jin-Shi Chen, born in 1983, is currently an associate professor at School of Mechanical and Aerospace Engineering, Jilin University, China.

E-mail: spreading@jlu.edu.cn

Dong-Yang Huo, born in 1996, is currently a master candidate at School of Mechanical and Aerospace Engineering, Jilin University, China. 
Figures
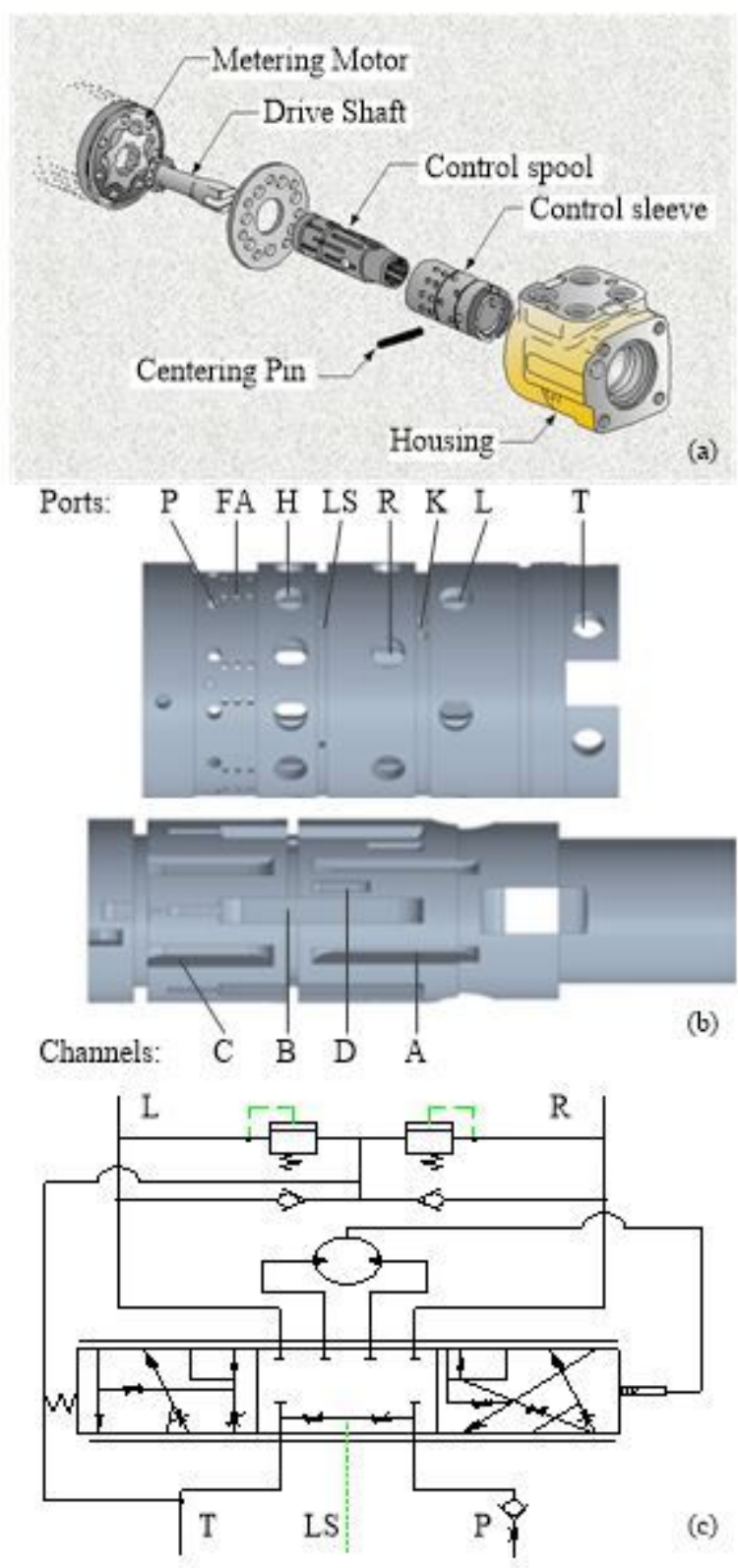

Figure 1

Schematic diagram of the redirector. (a) Structure of the redirector; (b) Structure of the rotary valve; (c) Principle diagram of the redirector. 


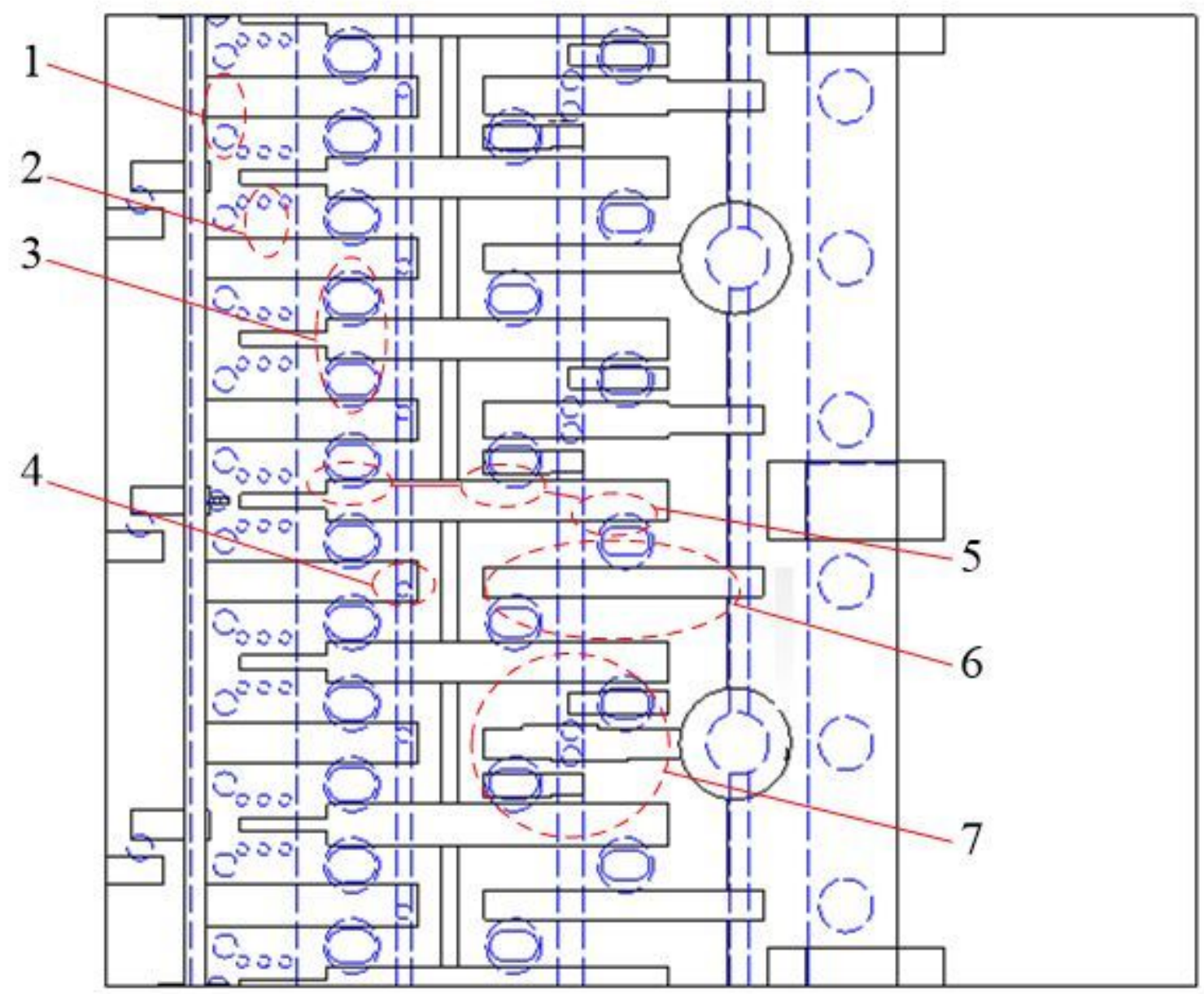

Figure 2

Expanded view of control spool and sleeve. 1. Inlet module; 2. Flow rate amplification module; 3. Metering motor module; 4. Load sensor module; 5. Working module; 6. Return module; 7. By-pass module.

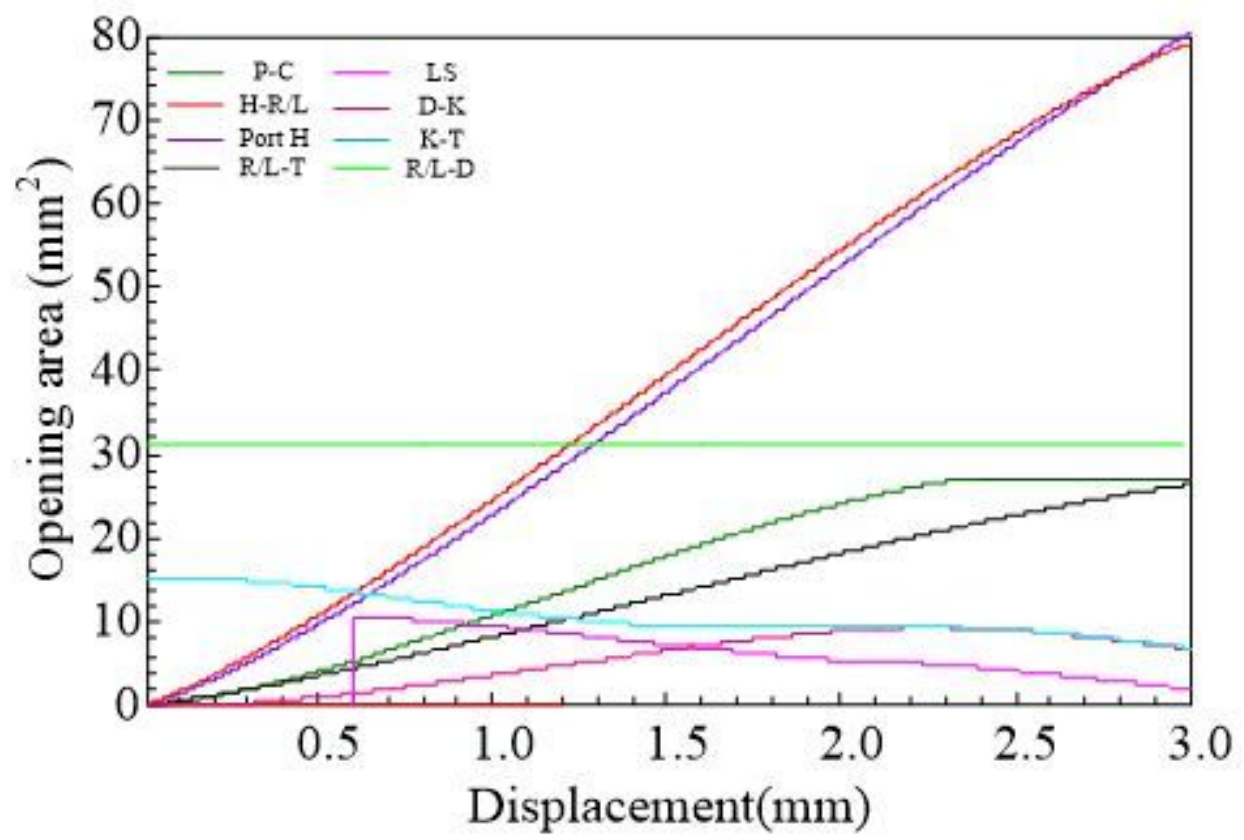


Figure 3

Relation between the opening area of each module and the control spool displacement

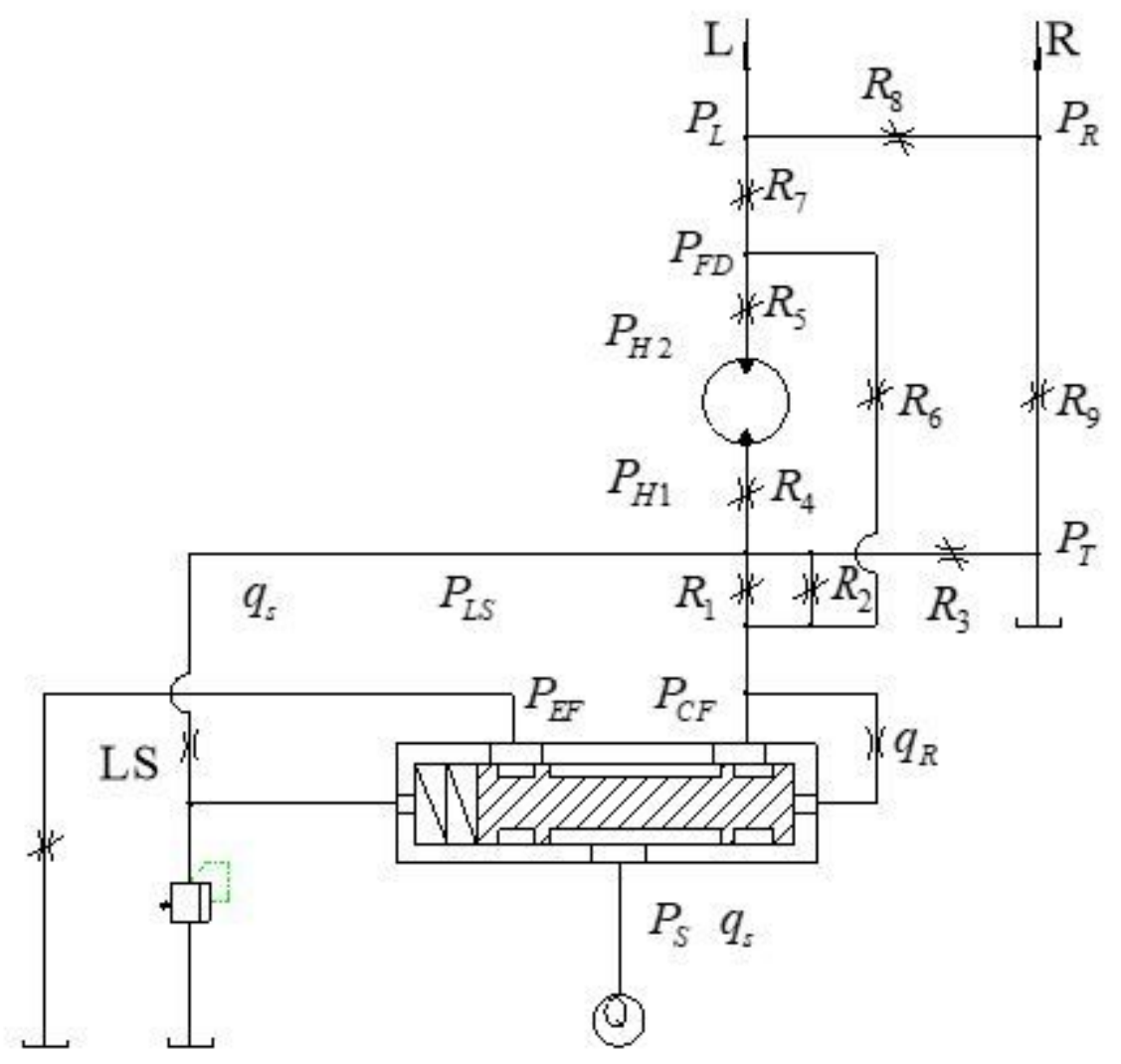

\section{Figure 4}

Schematic diagram of the equivalent damping

(2)

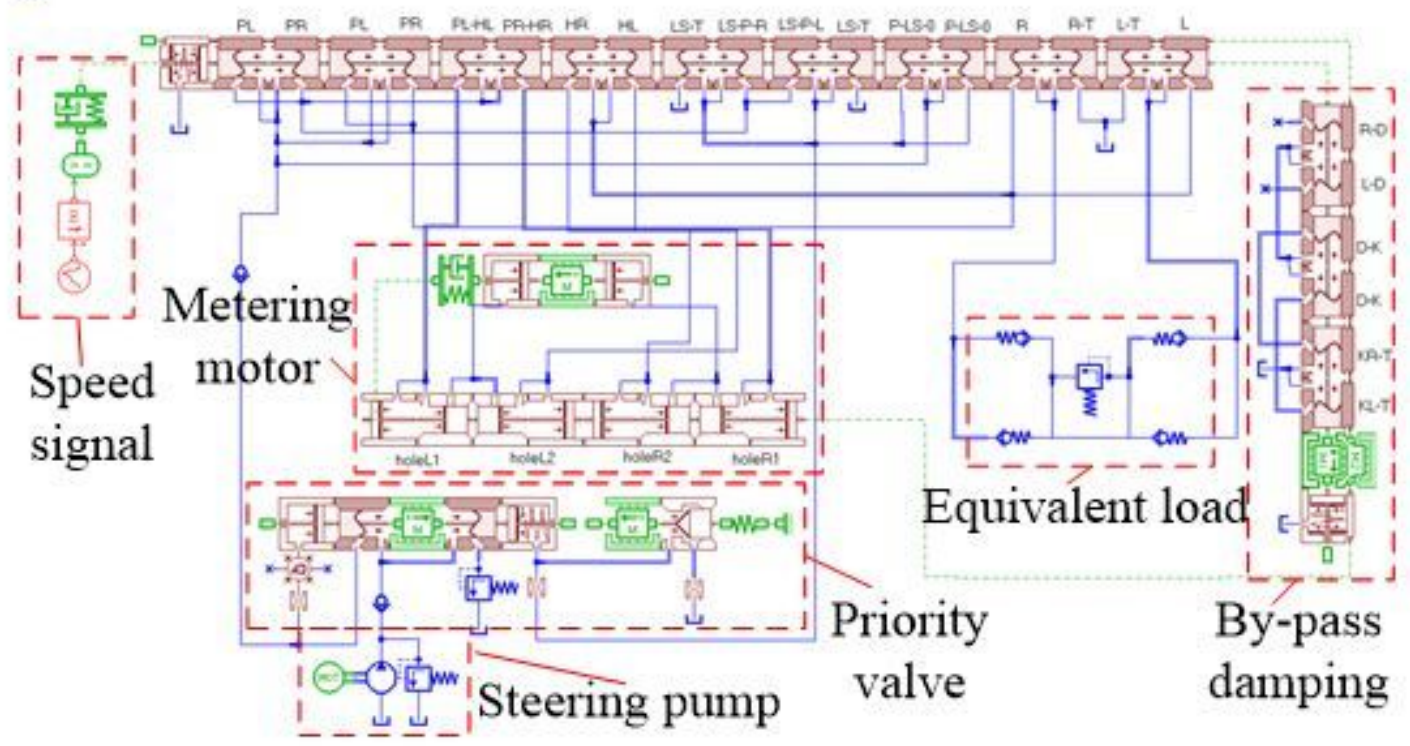

Figure 5 
Simulation model of the novel redirector.

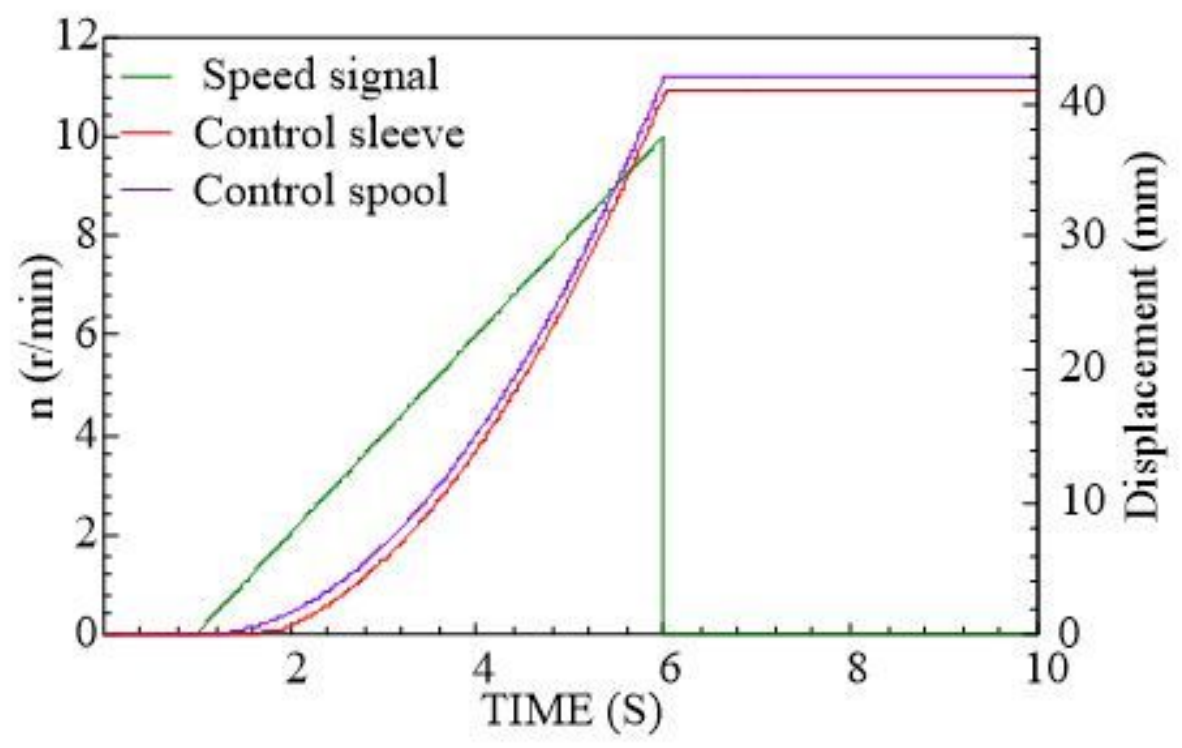

Figure 6

Displacement of control spool and sleeve.

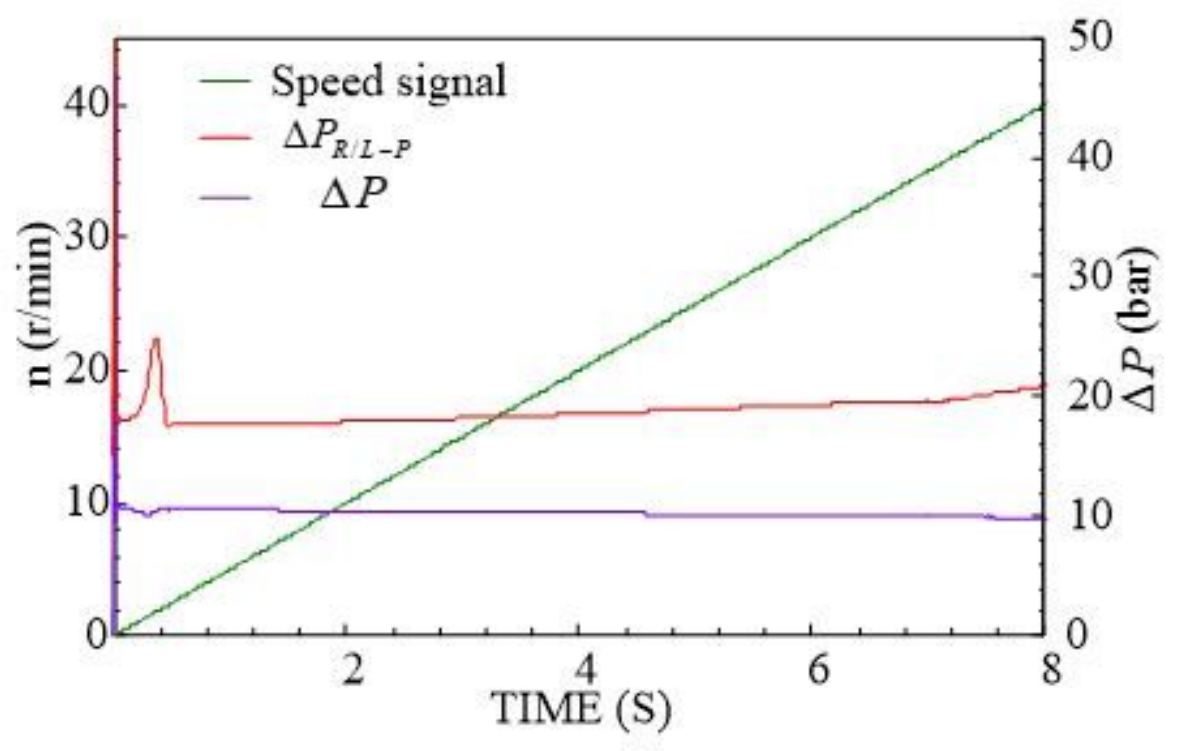

Figure 7

Relation between speed signal and, . 

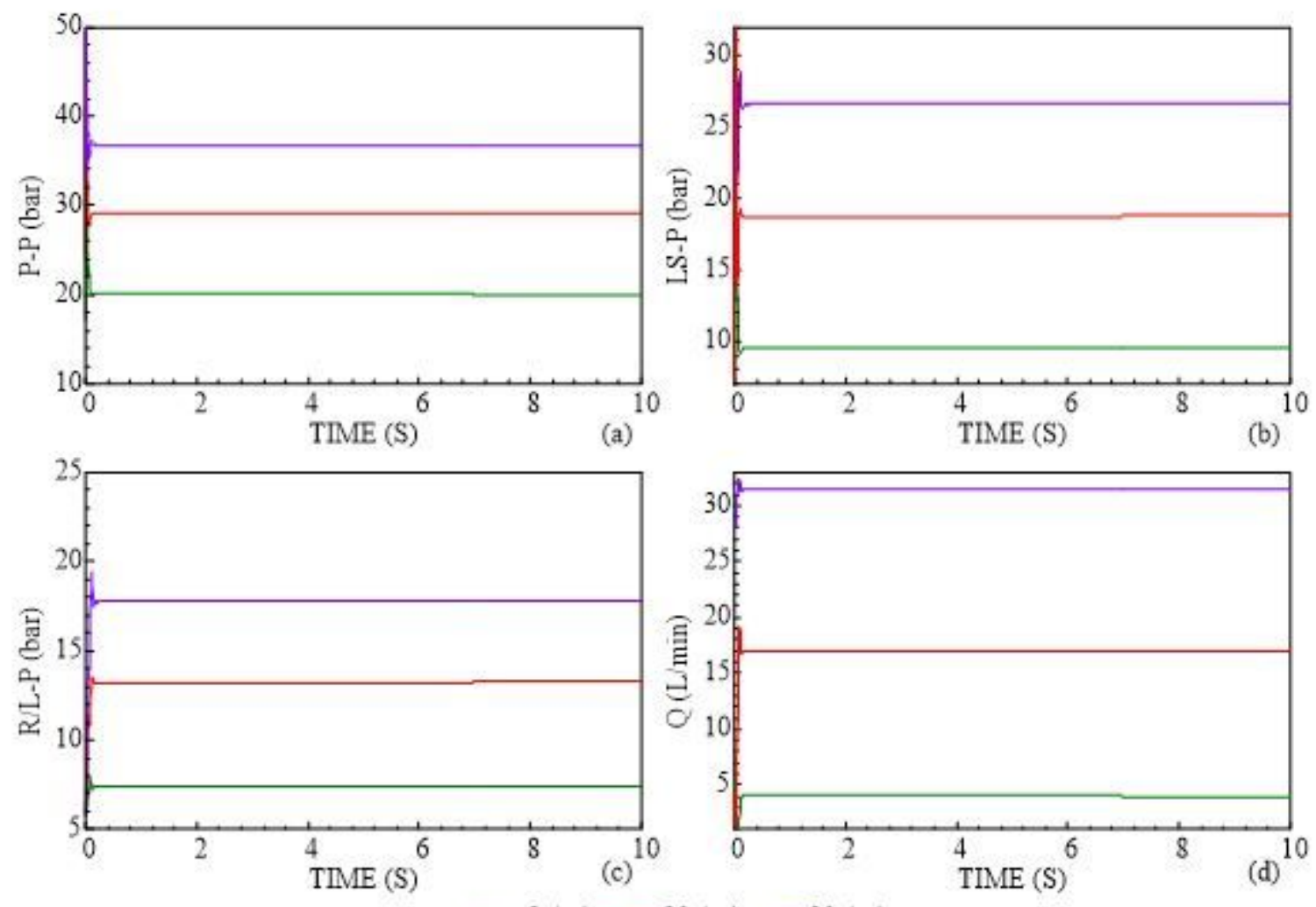

- $8 \mathrm{r} / \mathrm{min}-20 \mathrm{r} / \mathrm{min}-30 \mathrm{r} / \mathrm{min}$

Figure 8

Simulation results under no-load condition of electromotor speed is $708 \mathrm{r} / \mathrm{min}$. (a) ; (b) ; (c) ; (d)
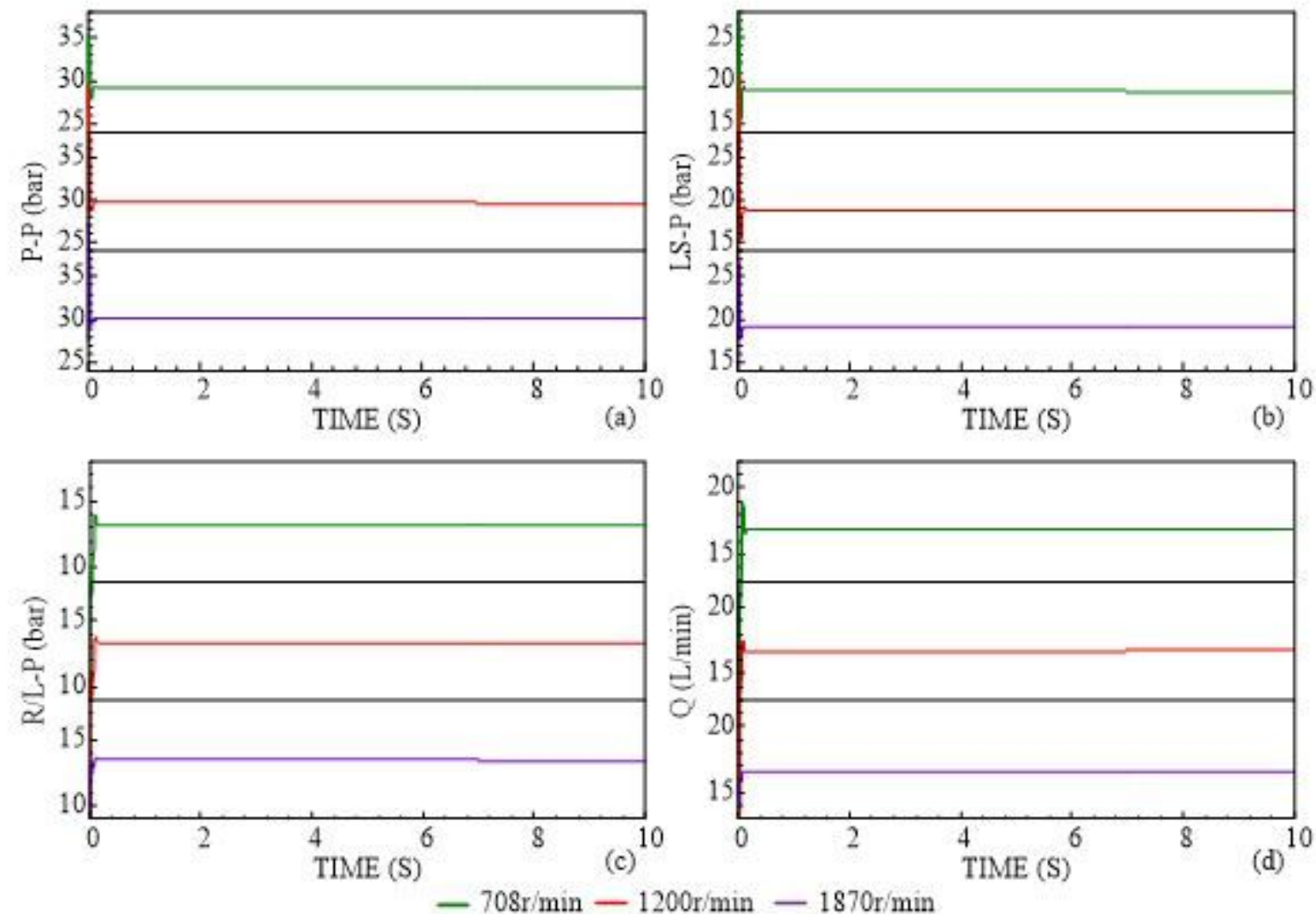

$$
-708 \mathrm{r} / \mathrm{min}-1200 \mathrm{r} / \mathrm{min}-1870 \mathrm{r} / \mathrm{min}
$$


Figure 9

Simulation results under no-load condition of steering wheel speed is $20 \mathrm{r} / \mathrm{min}$. (a) ; (b) ; (c) ; (d)
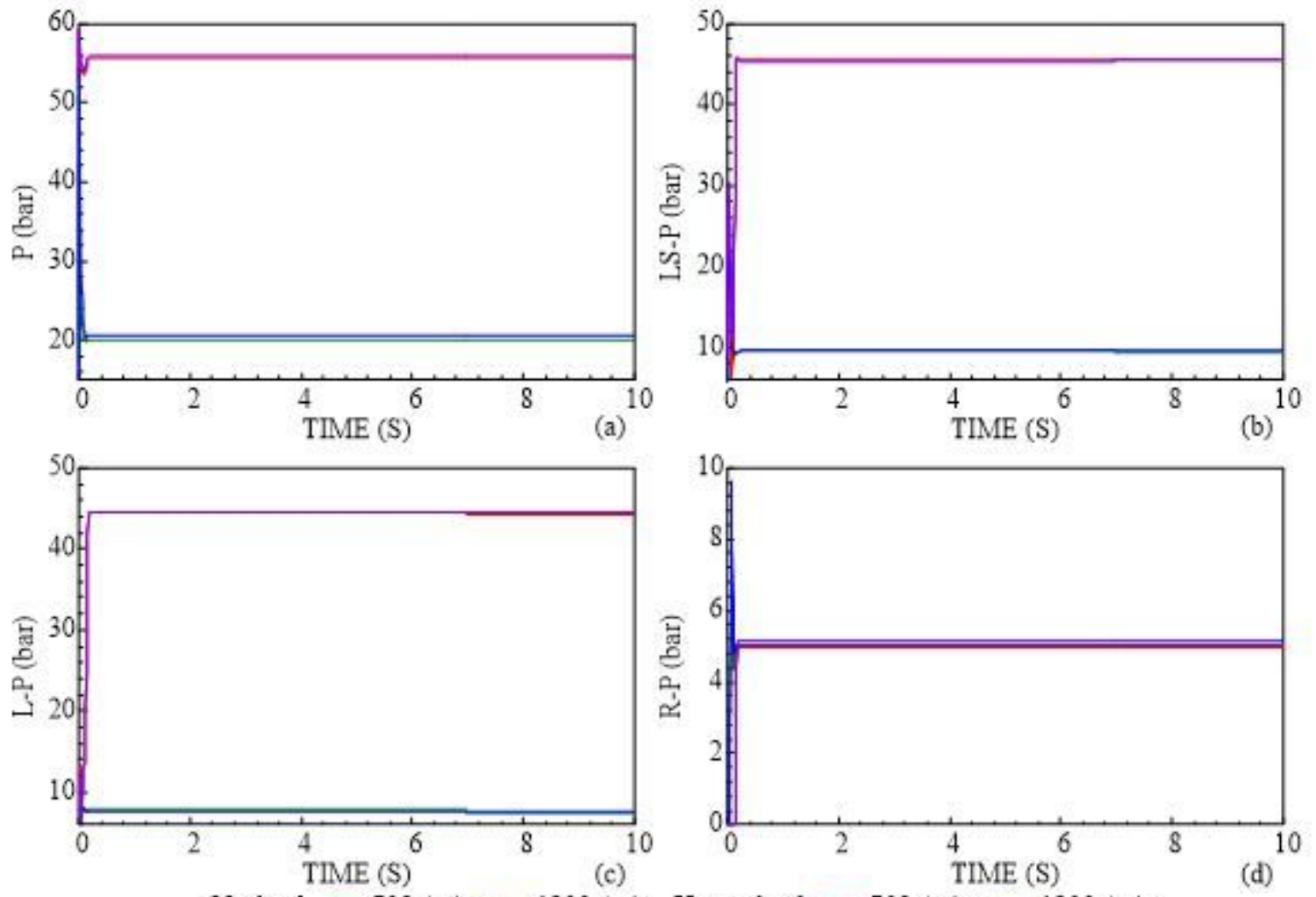

No-load $-708 \mathrm{r} / \mathrm{min}-1200 \mathrm{r} / \mathrm{min}$ Heavy-load $-708 \mathrm{r} / \mathrm{min}-1200 \mathrm{r} / \mathrm{min}$

Figure 10

Simulation results under steering wheel speed $8 \mathrm{r} / \mathrm{min}$, electromotor speed is $708 \mathrm{r} / \mathrm{min}$. (a) ; (b) ; (c) ; (d)

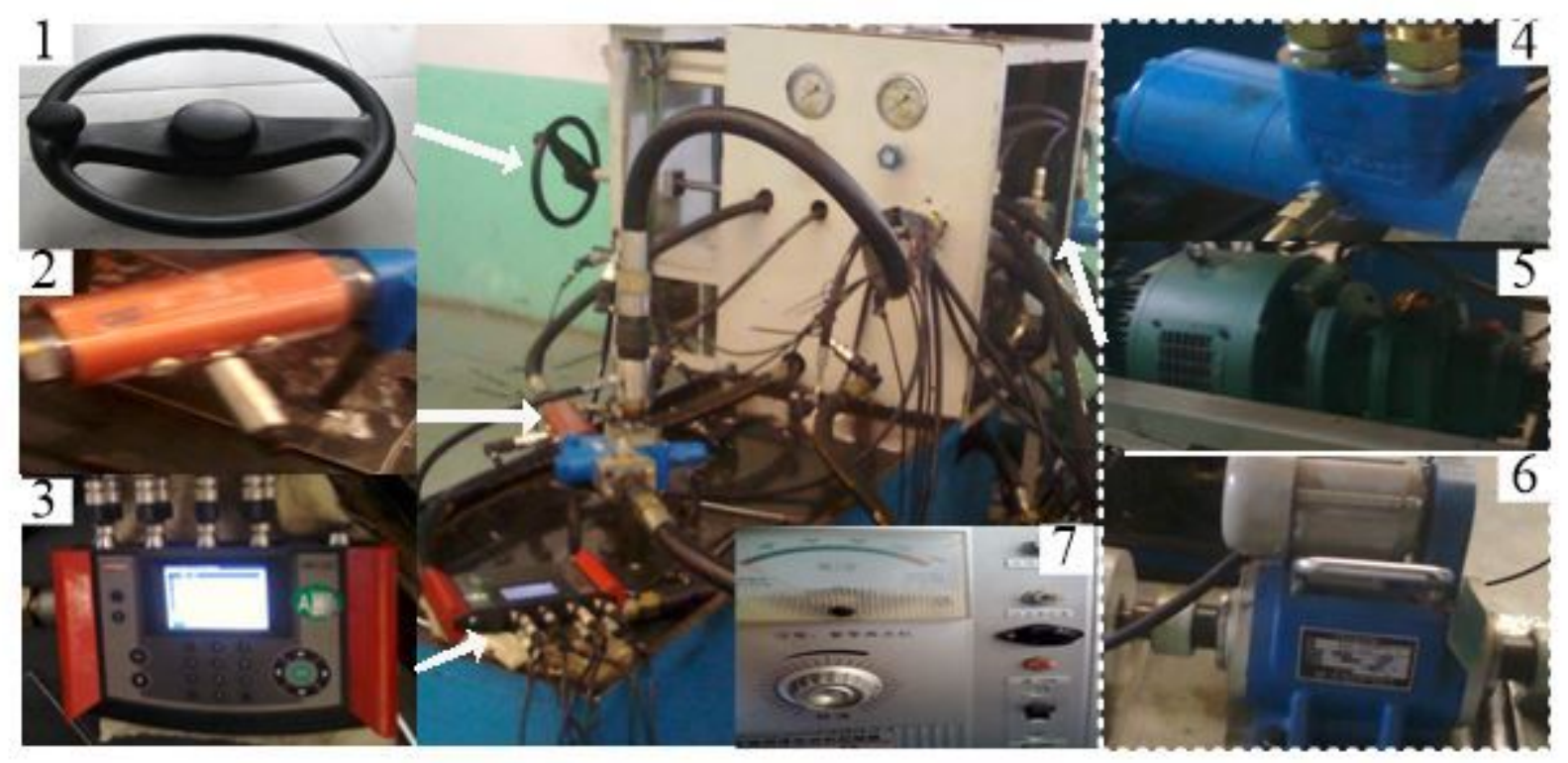


Photograph of the redirector experiment platform. 1. Steering wheel; 2.Pressure sensor; 3. Data acquisition; 4. Redirector; 5. Pump; 6. Electromotor; 7. Controller.
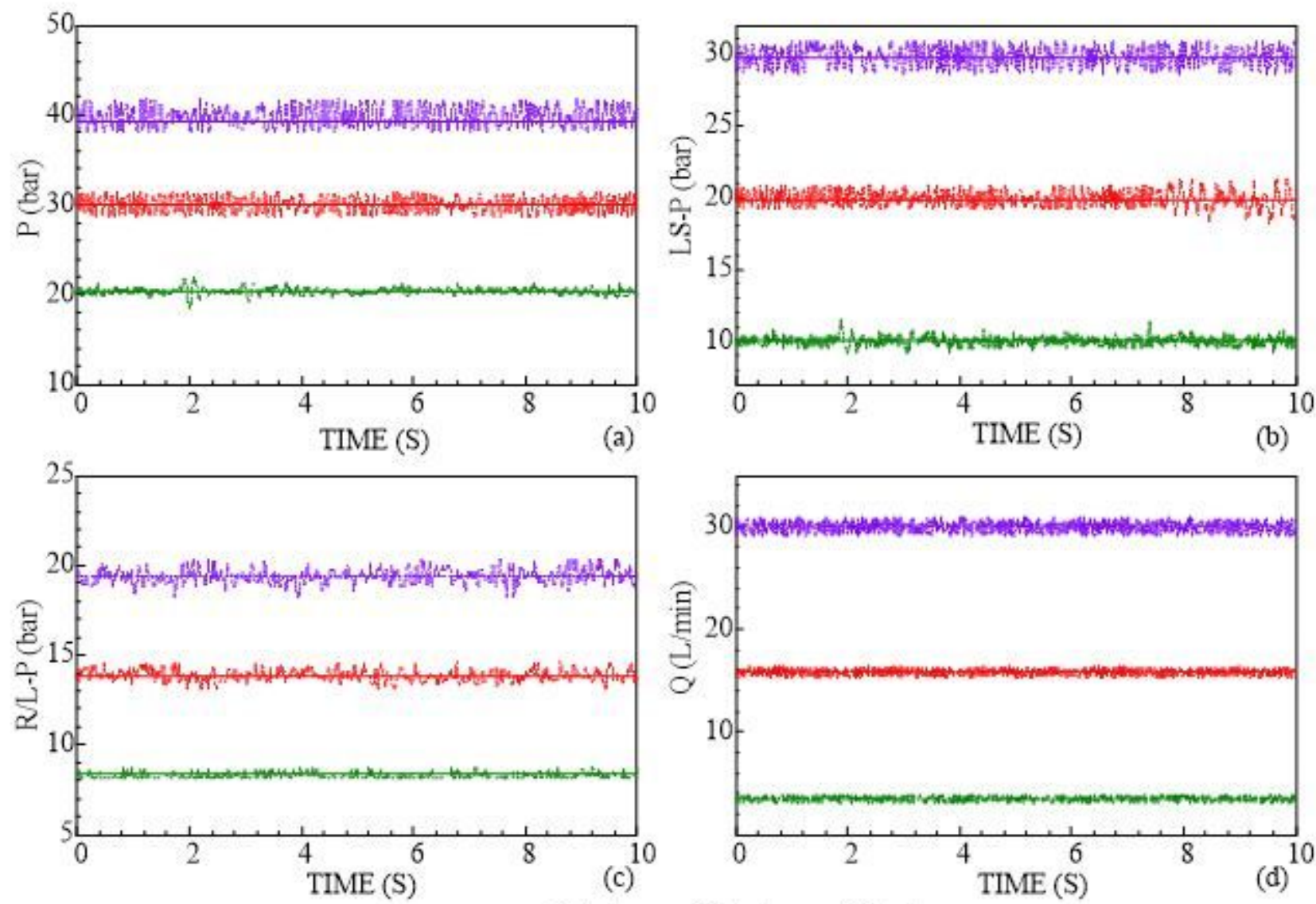

$-8 \mathrm{r} / \mathrm{min}-20 \mathrm{r} / \mathrm{min}-30 \mathrm{r} / \mathrm{min}$

Figure 12

Experimental results under no-load condition of electromotor speed is $708 \mathrm{r} / \mathrm{min}$. (a) ; (b) ; (c) ; (d) 

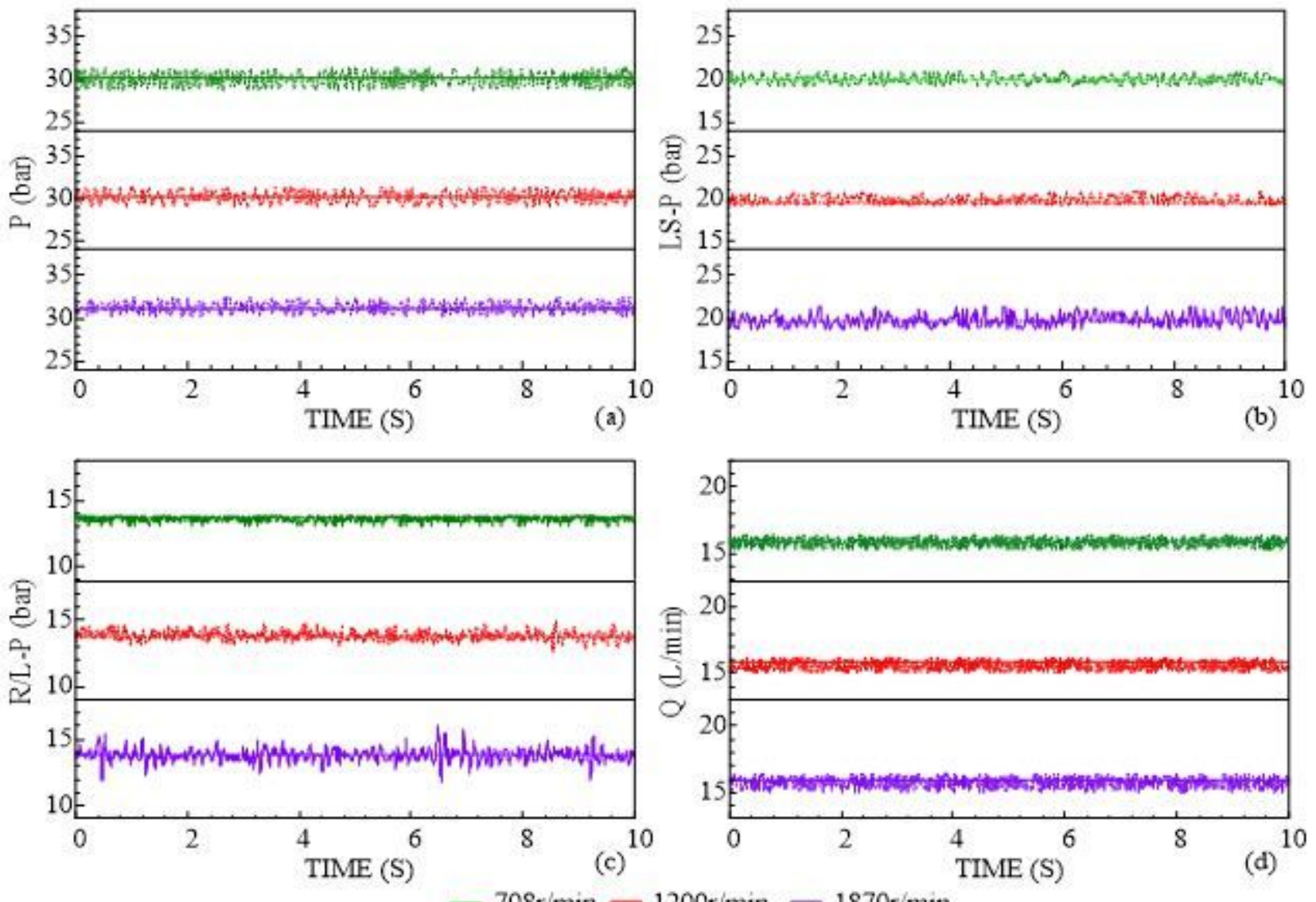

$-708 \mathrm{r} / \mathrm{min}-1200 \mathrm{r} / \mathrm{min}-1870 \mathrm{r} / \mathrm{min}$

\section{Figure 13}

Experimental results under no-load condition of steering wheel speed is $20 \mathrm{r} / \mathrm{min}$. (a) ; (b) ; (c) ; (d) 

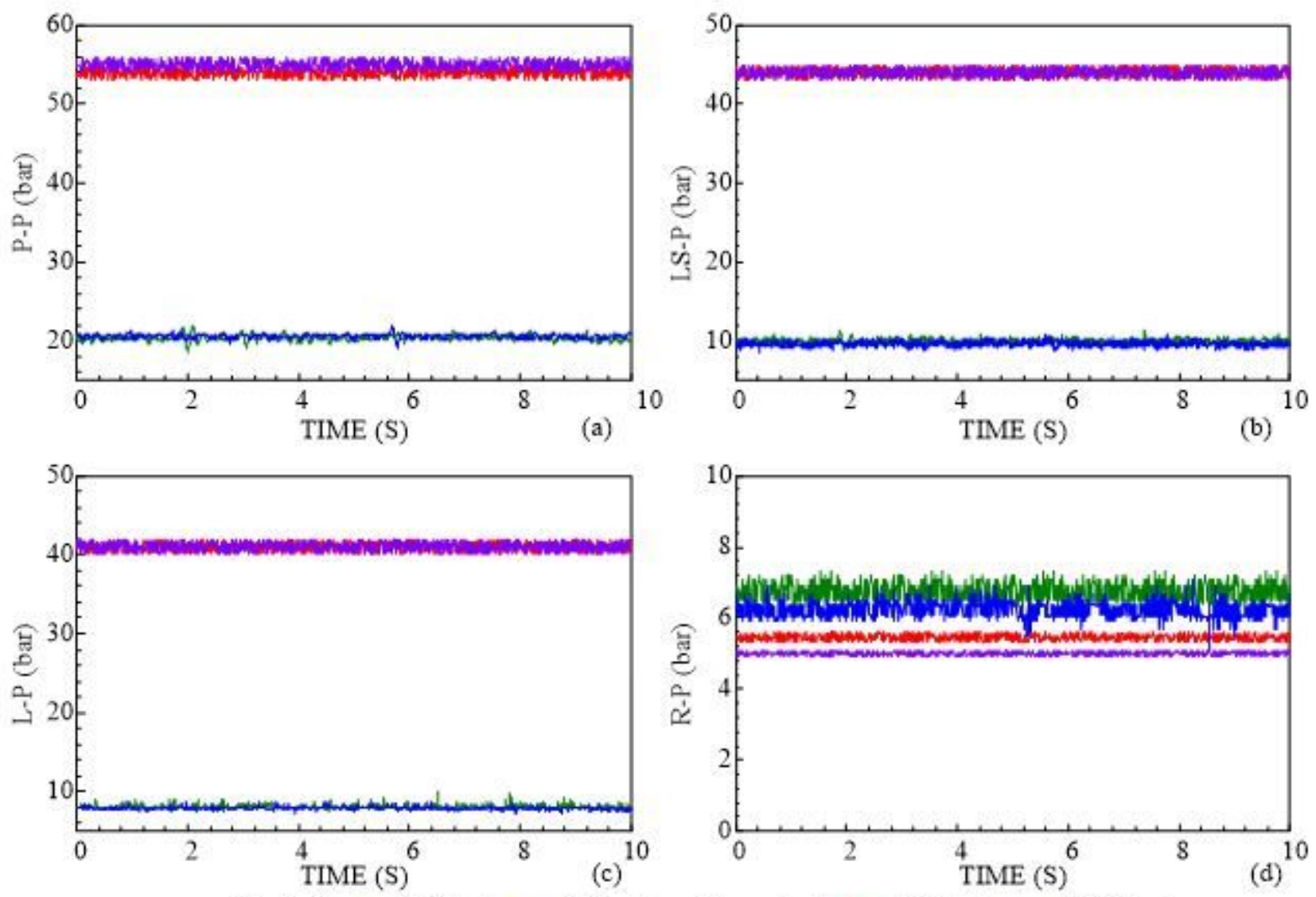

No-load $-708 \mathrm{r} / \mathrm{min}-1200 \mathrm{r} / \mathrm{min}$ Heavy-load $-708 \mathrm{r} / \mathrm{min}-1200 \mathrm{r} / \mathrm{min}$

\section{Figure 14}

Experimental results under steering wheel speed $8 \mathrm{r} / \mathrm{min}$, electromotor speed is $708 \mathrm{r} / \mathrm{min}$. (a) ; (b) ; (c) ; (d)

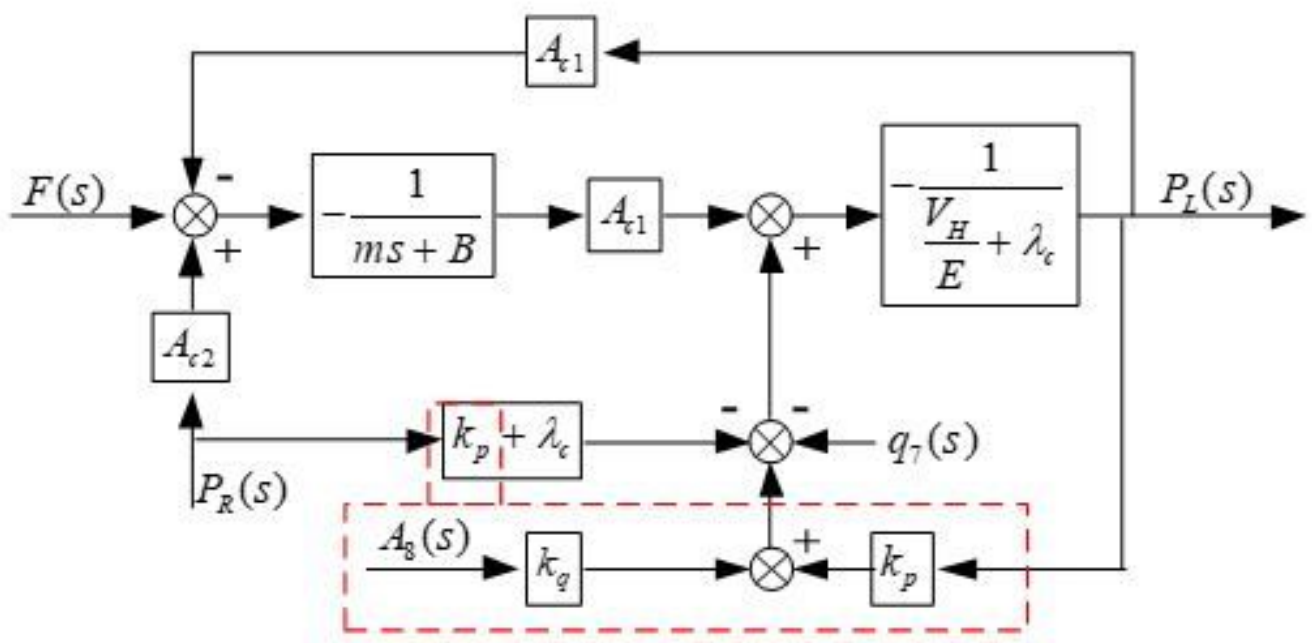

Figure 15

The schematic of redirector mathematical model 


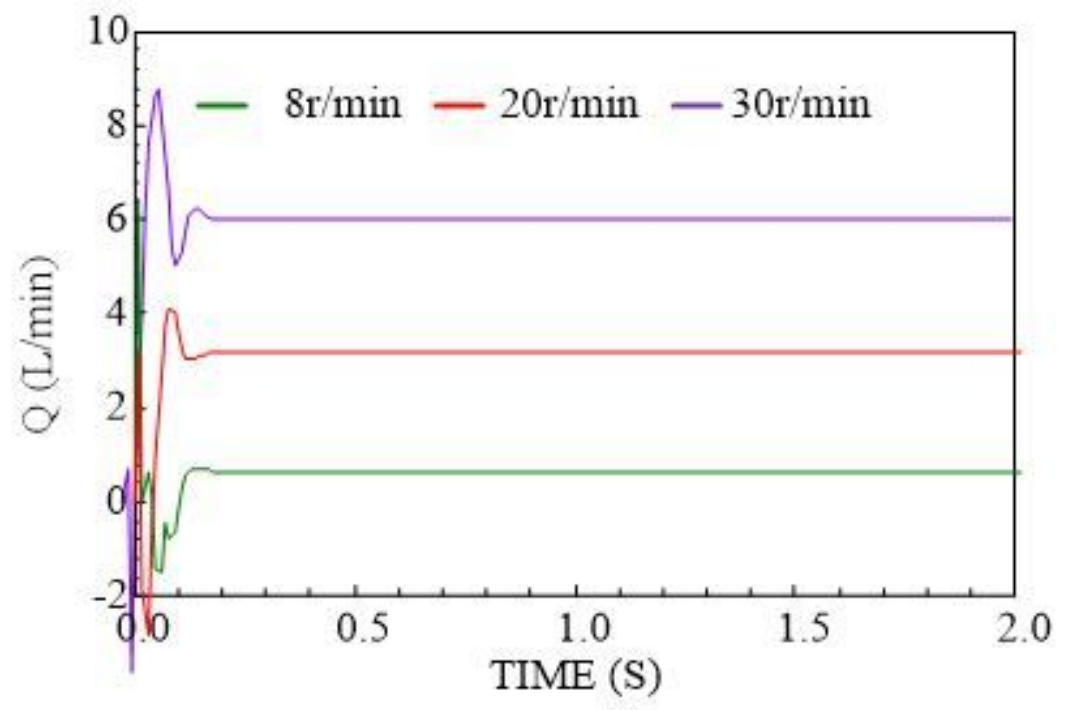

Figure 16

Flow rate through by-pass orifices.

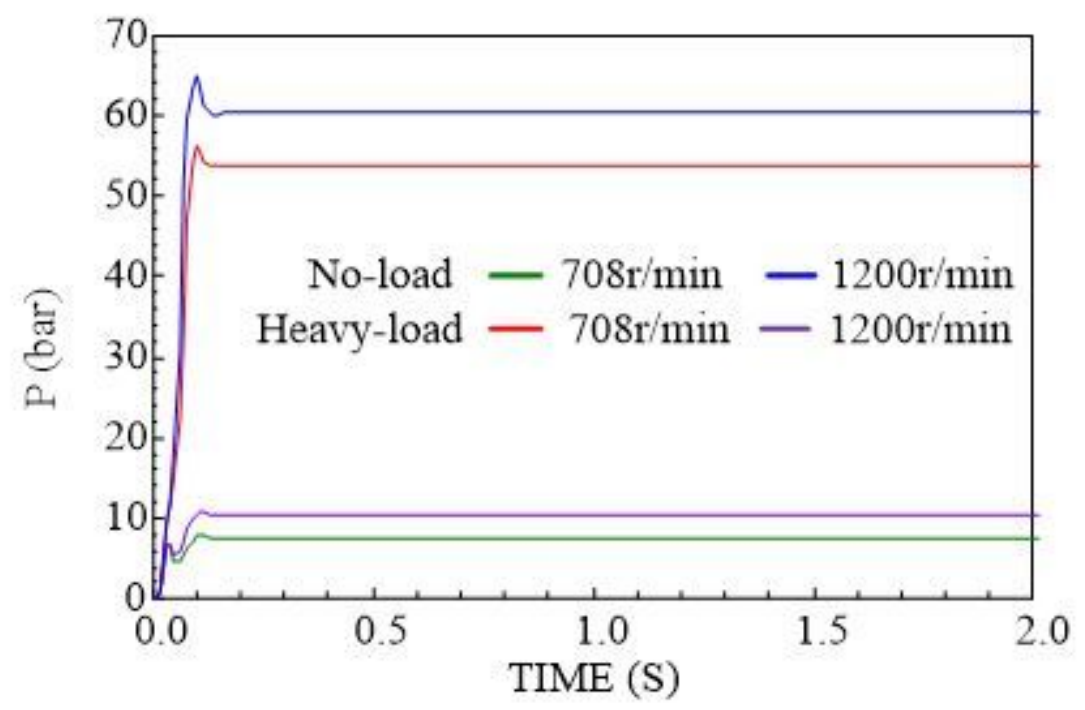

Figure 17

Pressure of the equivalent load inlet. 